\title{
A review on nanocomposite hydrogels and their biomedical applications
}

https://doi.org/10.1515/secm-2017-0161

Received May 9, 2017; accepted July 22, 2018

\begin{abstract}
In order to improve the drawbacks related to hydrogels, nanocomposite hydrogels were developed by incorporating different types of nanoparticles or nanostructures in the hydrogel network. This review categorizes nanocomposite hydrogels based on the type of their nanoparticle into four groups of carbon-, polymeric-, inorganic- and metallic-based nanocomposite hydrogels. Each type has specific properties that make them appropriate for a special purpose. This is mainly attributed to the improvement of interactions between nanoparticles and polymeric chains and to the enhancement of desirable properties for target applications. The focus of this paper is on biomedical applications of nanocomposite hydrogels and the most recent approaches made to fulfill their current limitations.
\end{abstract}

Keywords: biomedical applications; hydrogels; nanocomposite hydrogels; nanoparticles; nanostructures.

\section{Introduction}

The combination of nanotechnology with other fields of science has attracted increasing attention during the past decades. There have been numerous approaches to incorporate nano-scale methods with conventional methods toward manufacturing improved materials. Nanocomposite hydrogels are one example of such a combination between nanotechnology and biomaterial science.

\footnotetext{
*Corresponding author: Hamid Mahdavi, Department of Novel Drug Delivery Systems, Iran Polymer and Petrochemical Institute, 15 km Tehran-Karaj Highway, Pajuhesh Science and Technology Park, Pajuhesh Boulevard, Tehran, Iran; and Department of Biomedical Engineering, Islamic Azad University, Central Tehran Branch, PO Box: 112/14975, Tehran, Iran, Fax: +98 2148662507 , e-mail: h.mahdavi@ippi.ac.ir

Shirin Rafieian and Mir Esmaeil Masoumi: Department of Chemical Engineering, Islamic Azad University, North Tehran Branch, Tehran, Iran

Hamid Mirzadeh: Polymer and Color Engineering Department, Amirkabir University of Technology, Tehran, Iran
}

Hydrogels are interconnected, natural/synthetic polymer chains that are connected to each other by crosslinkers to produce a hydrophilic material with the macromolecular structure of a gel. They can swell several times their dry weight and may contain up to $99 \%$ water or biological fluids [1]. This three-dimensional (3D) highly hydrated porous network can mimic the native tissue microenvironment and they are typically designed to hold, release or capture materials $[1,2]$.

There are two types of hydrogels based on the production method: chemical (thermosetting) gels and physical (thermoplastic) gels. Chemical gels are cross-linked covalently through different methods, such as polymerization in the presence of a cross-linker or cross-linking of an existing polymer with different routes like heating, ultrasound, UV or $\gamma$-irradiation, etc. Physical gels are amorphous networks of hydrophilic polymers held together by noncovalent interactions, such as Van der waals forces, hydrogen bonding, etc. Chemical gels swell but do not dissolve in water, whereas physical gels eventually dissolve in water and may be melted by applied heat [3].

In selecting materials for preparing a hydrogel, important properties should be considered, including swelling, mechanical properties, diffusion rates and chemical functionality. These properties depend on the cross-linking density, the distance between cross-links, the macromolecular structures in the gel and on the residual chemicals (monomers, initiators, etc.) [3].

One of the disadvantages of hydrogels is their low mechanical strength [4], especially when used as tissue engineering scaffolds or in any application that demands high mechanical strength with good tolerance of compression and good elasticity at the same time (e.g. cartilage tissues). Their low mechanical properties make them difficult to handle and load in different parts of the body. Recent approaches are shifting toward optimizing the mechanical and chemical properties of hydrogels for specific biomedical purposes.

The high surface-to-volume and aspect ratios of nanoparticles and nano-layers has made them a good choice for use in the network of polymeric materials [5]. The physical/chemical crosslinking of polymeric chains with different nano-scaled structures leads to a network with new exclusive properties, which is called a nanocomposite hydrogel $[1,2]$. Novel properties and behaviors 


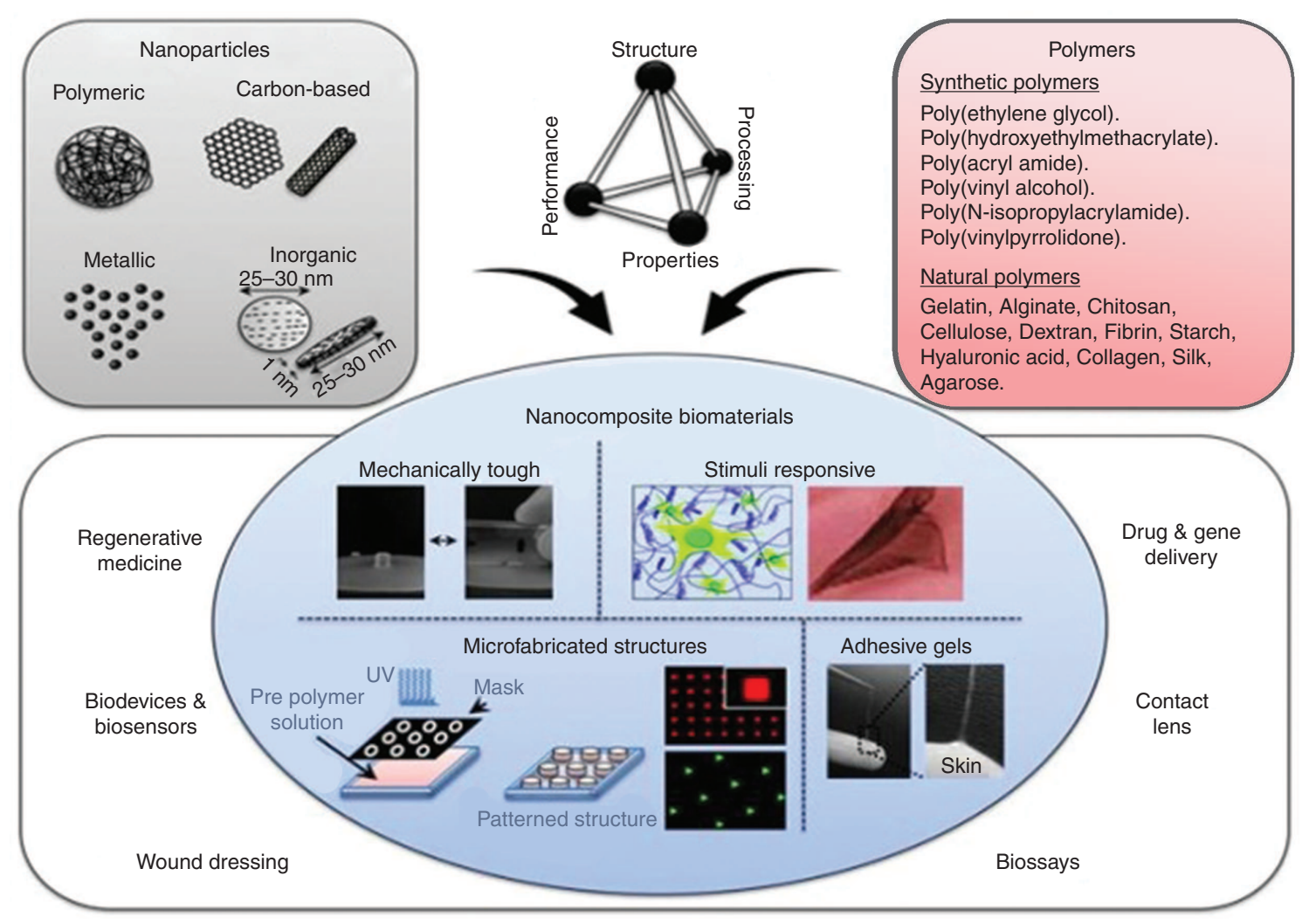

Figure 1: The nanocomposite hydrogels for biomedical applications. Adapted from Ref. [2], Copyright (2013), with permission from John Wiley \& Sons, Inc.

are observed after the nanoscale dispersion of fillers in the composite. Such dispersion can also improve some properties that already exist in the unfilled matrices $[1,6]$.

Nanomaterials with different bases are used to attain nanocomposite hydrogels. Carbon-based nanomaterials (carbon nanotubes or CNTs, graphene, nanodiamonds), polymeric nanoparticles (dendrimers and hyperbranched polymers), inorganic/ceramic nanoparticles (hydroxyapatite, silicates and calcium phosphate) and metal/metaloxide nanoparticles (gold, silver and ironoxides) are some examples of these nanomaterials [2] (Figure 1). This incorporation adds unique properties into hydrogels including the following [2]:

- Stimuli responsiveness to radiation, temperature and electric or magnetic field. Stimuli may induce swelling, water expulsion and absorption and the release of contents captured inside the network. The smaller the hydrogel, the faster is the response [3]. This property makes hydrogels a potential candidate for drug/gene delivery and biodevices/biosensors.

- Mechanical toughness, which is caused by the increase in entanglements of polymer network due to the incorporation of nanoparticles. Nanoparticles play the role of bridges between the polymer chains. The optimized mechanical strength is a vital property for biomaterials used in regenerative medicine, wound dressings and contact lenses.

- Adhesion to surfaces, especially skin or soft tissues, which makes hydrogels a potential wound dressing material with ease of load/unload and handle on the body surface. This adhesion is due to the surface roughness of nanocomposites gained by incorporating nanoparticles in the network and interlocking into the irregularities of the target surface.

- Ability to produce microfabricated structures, which is a physical method of manufacturing structures with nano/micro scale components. Cells are mostly cultured on 2D surfaces. These classic culture conditions are drastically different from the native 3D tissue environment, which can lead to abnormal cell behavior. Thus, there is a need to develop 3D cell culture platforms that can mimic native tissue conditions. This requires producing cell-friendly biomaterials with microfabrication techniques.

In developing nanocomposites, the challenge is how to create macroscopic components that benefit from 


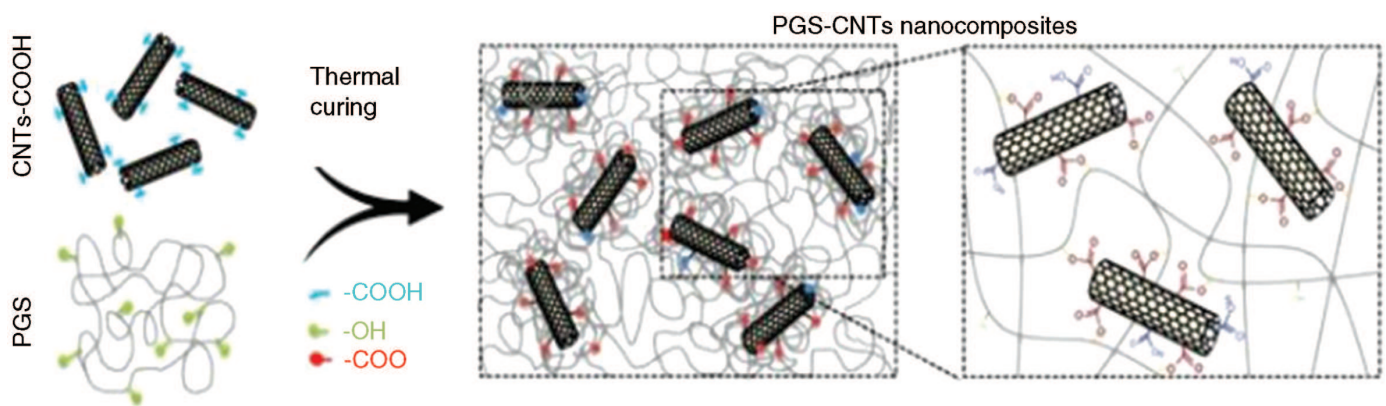

Figure 2: The synthesis and fabrication of PGS-CNT nanocomposites. Reproduced from Ref. [8] with permission of The Royal Society of Chemistry.

the unique physical and mechanical properties of the nanoscaled objects within them [5].

\section{Carbon-based nanocomposite hydrogels}

The carbon-based nanomaterials, such as carbon nanotubes (CNTs), graphene, fullerene (C60) and nanodiamonds, have potential applications in biomedicine. Especially, CNTs and graphene are widely used due to their high electrical conductivity, mechanical strength, and optical properties. CNTs are hollow cylindrical tubes consisting of carbon (graphite) with a high aspect ratio $(\sim 1000)$ and $\mathrm{sp}^{2}$ hybridization. Perfect (defect-free) CNTs differ from graphite in very low percentage or even the absence of chemically active dangling bonds. A feature of CNT is the variety of specific distances that are due to the Van der Waals forces. CNT pores are readily accessible to ions of different sizes and charges. The charging mechanism is described by the equation below [7].

$$
\text { , } \mathrm{C}=\mathrm{O}+\mathrm{H}^{+}+\mathrm{e}^{-} \longrightarrow \frac{\mathrm{y}}{\mathrm{C}} \mathrm{COH}
$$

Containing these properties, carbon-based nanomaterials are good candidates for engineering electrically conductive tissues, such as nerve, muscle, and cardiac tissues [2]. The rigidity of CNTs is due to the strength of the C-C bonds in individual shells. Moreover, CNTs can act as a nanoscale heat sink, which prevents the composite material from over-heating and destruction. The optical properties of CNTs are strongly affected by the symmetry, the presence or absence of the cap (CNT ends) and the number of constituent carbon atoms [7].

\subsection{Carbon nanotubes}

The hydrophobic nature of carbon-based materials limits their interaction with hydrophilic polymers. For this reason, CNT surfaces are modified with various polar groups, such as amines $\left(\mathrm{NH}_{2}\right)$, hydroxyls $(\mathrm{OH})$ and carboxyls $(\mathrm{COOH})$, or grafted with different polymer chains in order to enhance their dispersion (Figure 2) [2].

CNTs can be used as reinforcing agents within hydrogel networks and, in some cases, make the hydrogel responsive to external electrical or thermal stimuli. The addition of $1 \%$ CNTs to poly glycerol sebacate (PGS)-based hydrogels reinforces the polymer network. The hydroxyl groups on the PGS esterifies with the carboxylic groups present on the $\mathrm{COOH}$-functionalized CNTs. Here, the CNTs act as both physical and covalent crosslinkers. This covalent crosslinking between the CNTs and polymer chains results in a significant increase in the tensile and compression modulus compared to pure PGS, although the elasticity of the polymer network is not compromised. As a result, the addition of CNTs changes the ductile fracture property of PGS to a brittle fracture property and an elastomeric stiff nanocomposite is obtained (Figure 3) [8].

\subsection{Graphene/Graphene-oxide}

Graphene sheets are treated with strong oxidizers in an intense acid environment or by radiation to attach oxygencontaining groups on their surface and obtain graphene oxide (GO). GO is more hydrophilic but less electroconductive in comparison to graphene. GO sheets can be reduced again with reduction agents and the heating process but they will still contain oxygen-containing residuals.

In a recent report, gelatin methacrylate (GelMA) impregnated with functionalized GO (fGO) nanosheets, for the site-specific gene delivery of pro-angiogenic human vascular endothelial growth factor plasmid DNA $\left(\mathrm{pDNA}_{\mathrm{VEGF}}\right)$ to damaged cardiac tissues [9]. GO can be used to deliver genes efficiently when bonded to cationic polymers such as polyethyleneimine (PEI). While low molecular weight, branched PEI is known to have low cytotoxicity 


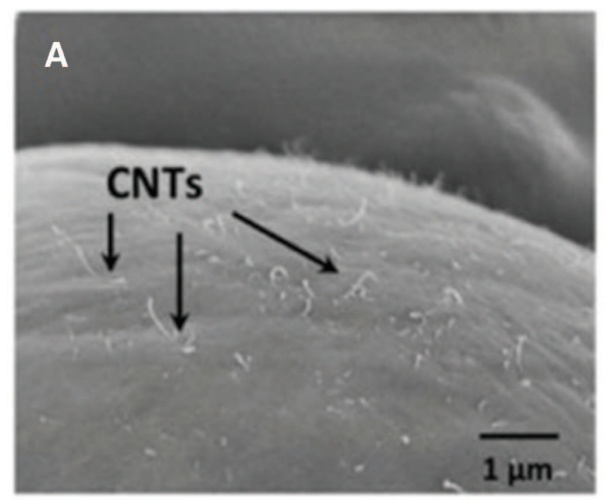

B
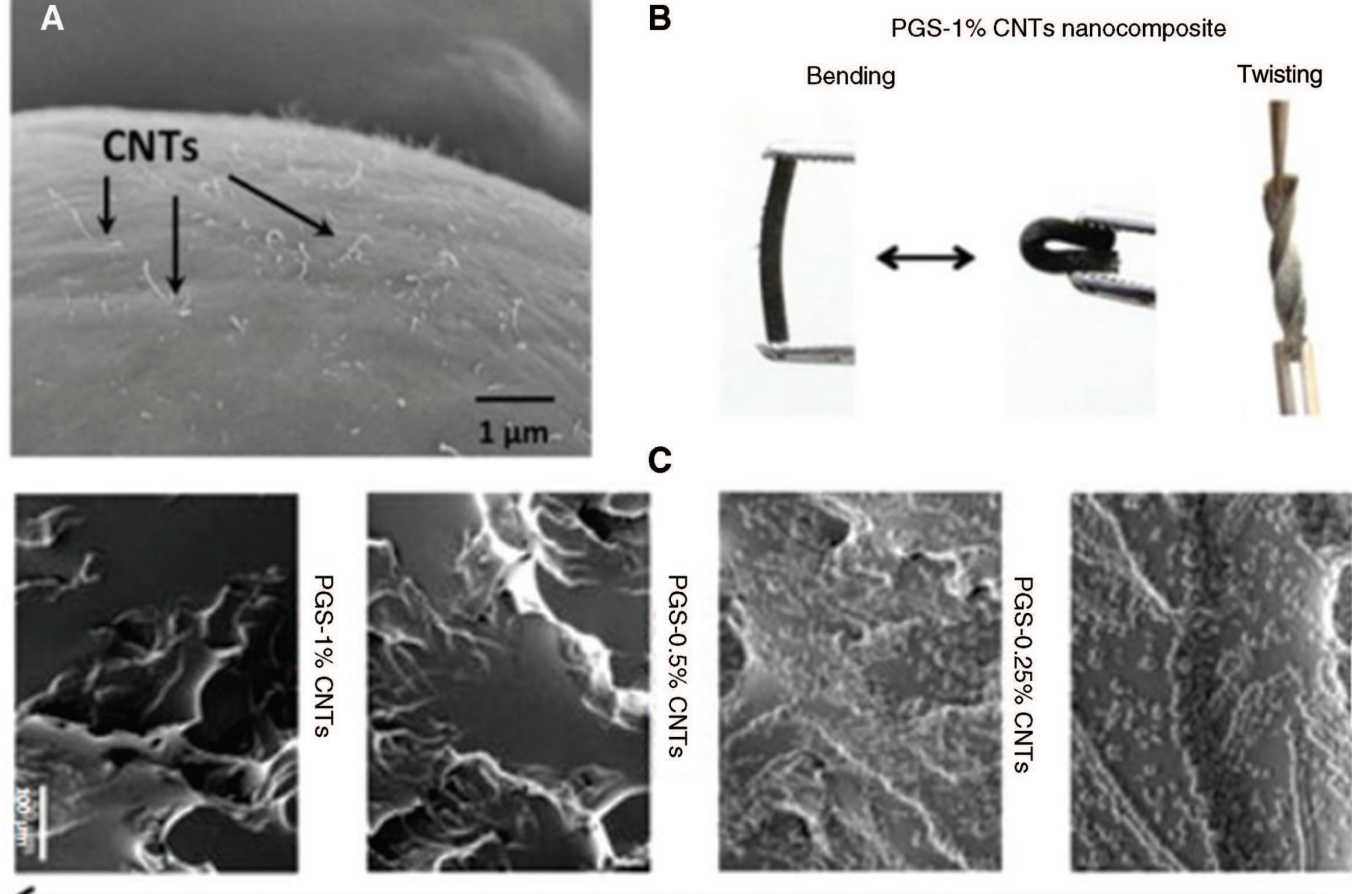

C

Brittle fracture
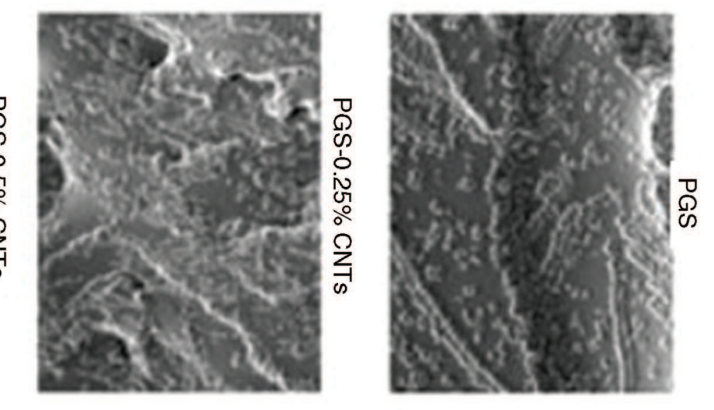

Ductile fracture

Figure 3: (A) The SEM image of the freeze-fractured surface of PGS-1\% CNT nanocomposites showing uniform distribution of CNTs on the surface. (B) PGS-CNT nanocomposites showing high flexibility and can sustain bending and twisting. (C) The SEM images of the fractured surfaces of PGS-CNT nanocomposites after tensile testing. Reproduced from Ref. [8] with permission of The Royal Society of Chemistry.

and binds strongly to DNA, it is an acceptable material for gene transfer and can enhance gene delivery efficiency in combination with GO. This is how $\mathrm{fGO}$ is produced [10-12]. GelMA is also nontoxic to cells if its concentration and degree of methacrylate are optimized [13]. This combination promotes local myocardial neovascularization at the injected sites and reduces fibrosis. The heart ejection fraction $(\% \mathrm{EF})$ and thus the heart function, is also improved, as shown in Figure 4 [9].

The dispersion of gold nanoparticles on GO or reduced $\mathrm{GO}$ ( $\mathrm{rGO}$ ) sheets or the encapsulation of gold clusters inside graphene-based cages generates a new class of hybrid materials for drug/gene delivery, bioimaging, electrochemical biosensing and photothermal therapy. The oxygen-containing functional groups on $\mathrm{GO}$ and $\mathrm{rGO}$ are essential for further chemical reactions and the integration of gold nanostructures through the electrostatic interactions, covalent linkage and $\pi-\pi$ stacking [14]. A scheme is shown in Figure 5.

Although carbon-based hydrogels are able to imitate some of the functions of native tissues, their long-term cytotoxicity as tissue replacements in the body should be considered; it also requires further investigations under in vitro and in vivo conditions [2].

\section{Polymer-based nanocomposite hydrogels}

Dendrimers or hyperbranched polymers, liposomes, polymeric micelles, nanogels and core shell polymeric particles are some examples of nanoparticles with the ability to entrap hydrophobic or hydrophilic drugs, proteins, genes and other bioactive agents. These hybrid hydrogels have gained attention in the pharmaceutical and biomedical areas due to their controlled drug release ability [15, 16]. This ability results from the stimuli-responsiveness of these polymeric nanoparticles. Stimuli-responsiveness means demonstrating a sharp change in properties upon a small change in environmental conditions like temperature, light, concentration or $\mathrm{pH}$.

Ionizable polymers with a $\mathrm{pk}_{\mathrm{a}}$ value between 3 and 10 are candidates for $\mathrm{pH}$-responsive systems. Weak acids and bases like carboxylic acids, phosphoric acids and amines, respectively exhibit a change in the ionization state upon variation of the $\mathrm{pH}$. This leads to a conformational change in the swelling behavior of the hydrogels when these ionizable groups are linked to the polymer structure [17]. 
A

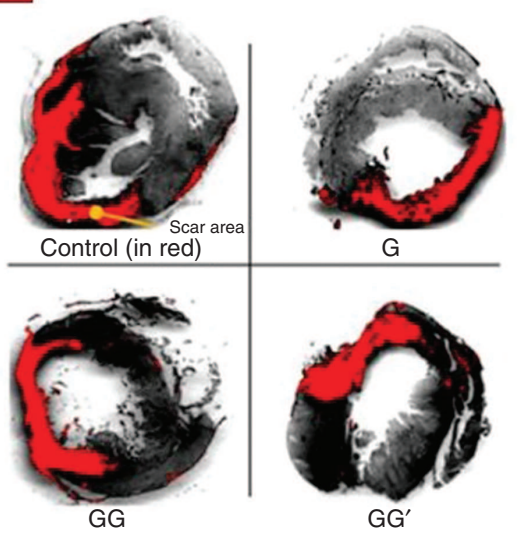

B

C
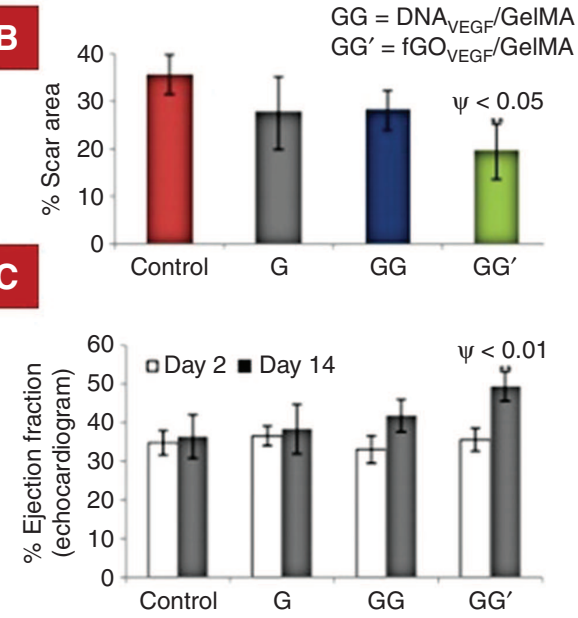

Figure 4: The assessment of the in vivo scar areas and cardiac function of infarcted hearts treated with GG' hydrogel (GelMA hydrogel carrying fGOVEGF (pDNA $\mathrm{VEGF}_{\mathrm{VEF}}$ bound to fGO)) therapy. (A) and (B) The scar area determination by morphometric analysis of the left ventricle in different groups. The representative images of the left ventricle myocardial sections stained with sirius red show the cardiac fibrosis regions (in red). Sham operated and untreated infarcted group were used as controls. The red area represents the ECM deposition in the scar tissue and the gray area represents the myocardium. (C) Echocardiographic assessment of cardiac function. The heart ejection fraction (EF\%) was monitored at days 2 and 14 post-treatment. $p<0.0001$; ${ }^{\star \star \star} p<0.001,{ }^{\star \star} p<0.01,{ }^{*} p<0.05$ vs. time-matched control $(n=7)$. The $p$-values comparing time-matched $\mathrm{GG}^{\prime}$ and $\mathrm{GG}$ are indicated by $\psi$. This is an unofficial adaption of Ref. [9] that appeared in an ACS publication. ACS has not endorsed the content of this adaption or the context of its use.

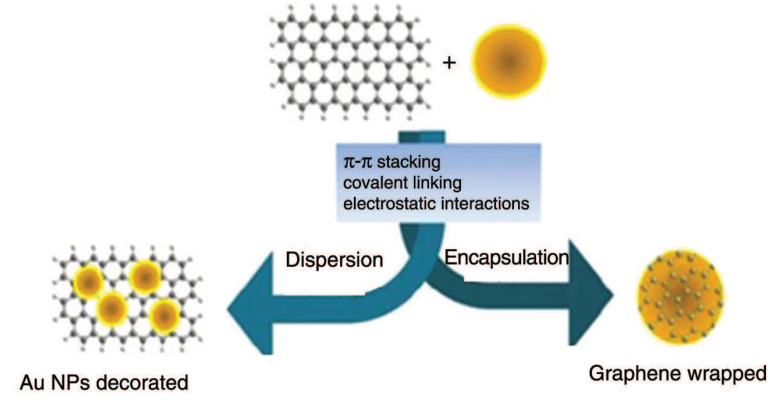

Figure 5: The decoration of $\mathrm{GO}$ and $\mathrm{rGO}$ with gold nanostructures using different interaction forces. Adapted from Ref. [14] with the permission of The Royal Society of Chemistry.

\subsection{Dendrimers/Hyperbranched polymers}

Dendrimers have high reactivity and loading efficiency due to the multiple functional groups on their periphery and their highly branched porous structure [2]. The stiffness of the hydrogels, the degradation properties, and the hydration kinetics are affected by the dendrimer concentration. The resulting nanocomposite hydrogels containing dendrimers show high stress absorbing capacity, which is crucial for cartilage tissue engineering applications. The globular morphology of chondrocytes encapsulated within the hydrogel nanocomposite is retained, and a significant increase is observed in the production of type II collagen and proteoglycans [18]. In another work, collagen-grafted nanocomposite films showed significant improvements in cell adhesion and proliferation due to the changes in wettability, surface morphology and new functional groups on the surface [19].

It has been observed that photocrosslinkable hyperbranched polyester (HPE) hydrogels can encapsulate hydrophobic drug molecules as a result of the hydrophobic structure inside their cavities. As the concentration of HPE increased, the functionalization of HPE with photocrosslinkable acrylate moieties resulted in formation of hydrogels with a highly porous interconnected structure, mechanically tough network and better attachment of fibroblasts on the surface (Figures 6 and 7) [20].

\subsection{Liposomes}

A liposome is a tiny bubble made out of the same material as a cell membrane (phospholipids). When membrane phospholipids are disrupted, they can reassemble themselves into tiny spheres, smaller than a normal cell, either as bilayers or monolayers. The bilayer structures are liposomes. The monolayer structures are called micelles. Liposomes are hydrophilic at the core and surface but hydrophobic at the shell layer. Hence, they can be loaded with hydrophobic and/or hydrophilic molecules, such as drugs, bioactive agents, DNA, RNA, and genes [21]. Drug-loaded liposomes, can be mixed with materials, such 

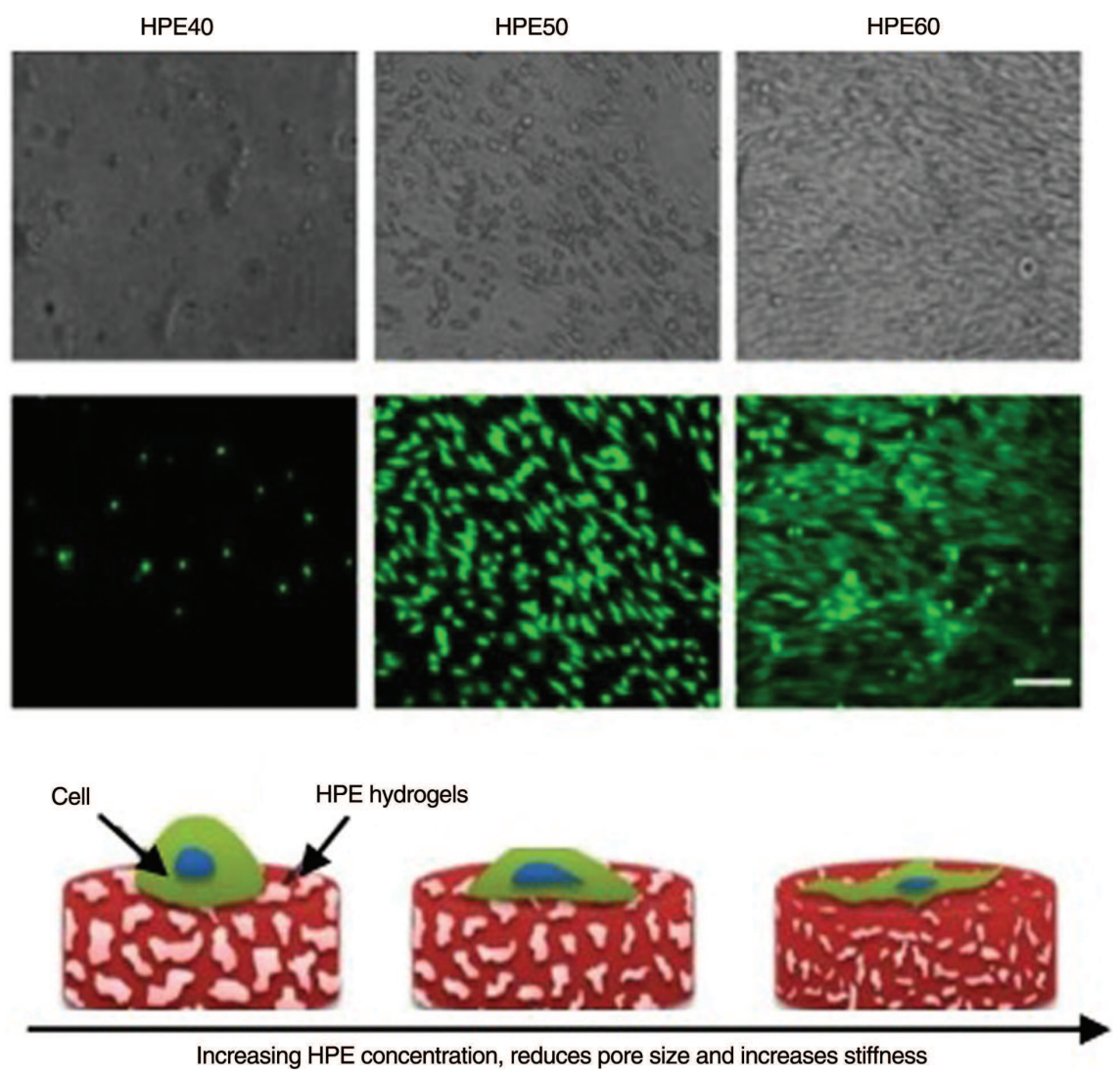

Figure 6: The representative phase contrast and fluorescent images of fibroblasts on the surface of the HPE hydrogels. Cells readily attached and spread on hydrogels with higher HPE concentration. Adapted with permission from Ref. [20]. Copyright (2013) American Chemical Society.
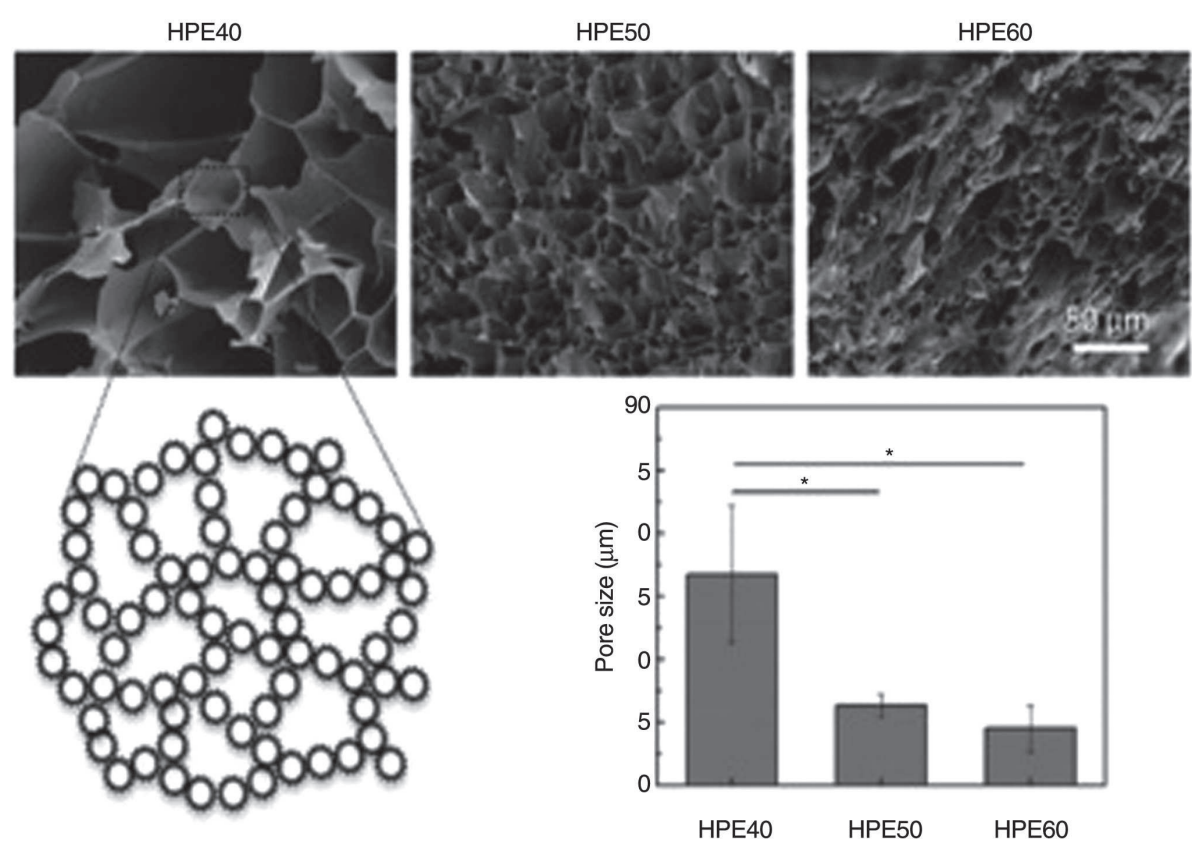

Figure 7: The effect of HPE macromolecule concentration on the microstructure of freeze-dried hydrogel network evaluated using SEM. Adapted with permission from Ref. [20], Copyright (2013) American Chemical Society. 


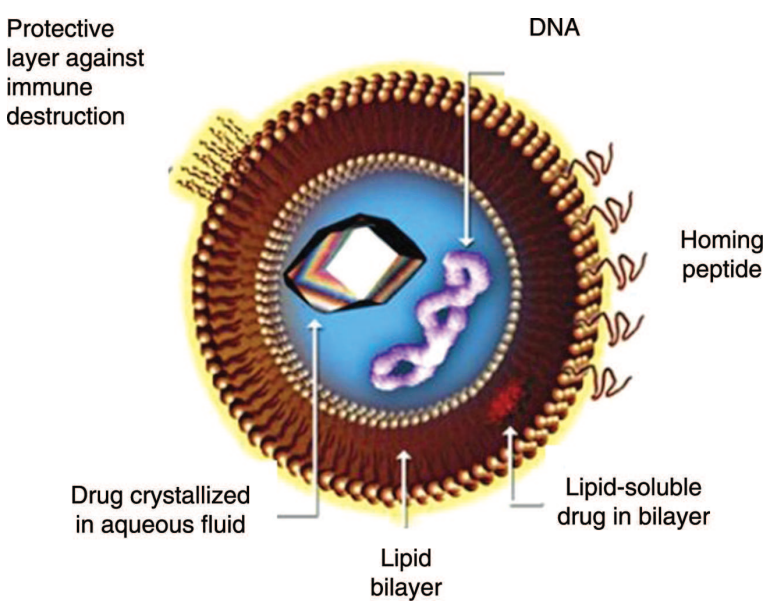

Figure 8: The structure of a liposome and its drug delivery mechanism. Image available at Ref. [21].

as degradable polymers, acting as a matrix or carrier in the system and then crosslinked to obtain nanocomposite hydrogels to deliver the molecules to a site of action (Figure 8).

\subsection{Nanogels}

Nanosize hydrogels (nanogels) can trap bioactive compounds inside their nanoscale core. They respond to microenvironmental elements, such as temperature or $\mathrm{pH}$, because of their nano-dimensions. Various methods are used to prepare nanogels based on their crosslinking route. They can be crosslinked either with covalent bonds (chemically) (Figure 9) or with hydrogen bonds as well as electrostatic and hydrophobic interactions (physically). For example, the amphiphilic block copolymers can self-assemble mono dispersive polymer micelles in water. Nanogels have been obtained by covalent cross-linking of the hydrophilic or hydrophobic polymer chains in these polymer micelles either at core or shell (Figure 9-A) [5].

Another route to obtain nanogels with a wellcontrolled size is through nano or microemulsion polymerization. This polymerization occurs within the core of oil-in-water or water-in-oil nano or microemulsions in the presence of surfactants (Figure 9-B). Monodispersed nanogels of various sizes have been synthesized using atom transfer radical polymerization (ATRP) in water-in-oil nanoemulsion. Water-soluble drugs, including anticancer drugs (e.g. doxorubicin) and bioactive macromolecules (e.g. DNA and proteins) can be easily incorporated into nanogels using this method [5, 22].

In a recent work, Poly(D, L-lactide-co-glycolide) (PLGA) micro/nanoparticles have been prepared using oil-in-oil emulsion/solvent evaporation in the presence of surfactants. Results indicate that the mean size of PLGA micro/nano particles is influenced by the polymer and surfactant concentration, stirring speed, impeller type and dropping size [23]. In addition, nanogels can be obtained using the aqueous cores of liposomes as reaction vessels. Nanogels with the size of the liposomal template are obtained after the removal of the lipid molecules covering the hydrogel. The lipid-coated nanogels can be used as nanocarriers (Figure 9-C) [24].

Nanogels can be used as nanoparticles in the construction of a hydrogel. Nanogel-integrated hydrogels (nanogel cross-linked gels) are attractive for drug delivery systems, regenerative medicine and bioimaging [5]. In an interesting application, synthesized poly(n-isopropylacrylamide) (PNIPAAm), a temperatureresponsive polymer, was coated on gold nanorods. The resulting core-shell nanocomposites were intravenously injected into mice, and the right kidney of each mouse was then exposed to near-IR laser irradiation (Figure 10-A). The organs were subsequently collected and the amount of gold nanorods in these organs was analyzed, as shown in Figure 10-B. Nanogels collapsed and aggregated during the on/off positions of the light source, according to diameter changes shown in Figure 10-C. The gold particles or any kind of encapsulated drug molecules within the nanogel core can be released in a controlled manner [25].

\section{Inorganic-based nanocomposite hydrogels}

Most of the inorganic nanoparticles, such as nanohydroxyapatite (nHA), synthetic silicate nanoparticles (nanoclays), bioactive glasses, silica, calcium phosphate, glass ceramic and wollastonite, are the essential minerals for normal tissue functions in the body [2]. These different types of ceramics are extensively used in implantable materials, especially for bone-related applications. Various types of chemical bonds can bond bone to ceramics [26], including the following:

- Direct covalent-ionic bond of a $\mathrm{PO}_{4}{ }^{3-}$ group attached to both an organic constituent of bone and the cation or oxygen ion on the surface of a ceramic;

- An electrostatic chemical bond between a positively charged amine group and a negatively charged oxygen surface of a ceramic;

- The hydrogen bonding of a hydroxyalated surface with the carboxyl group of an amino acid;

- The Van der Waals bonding of organic constituents inside a rigid hydrosphere with the negatively charged surface of the materials; 

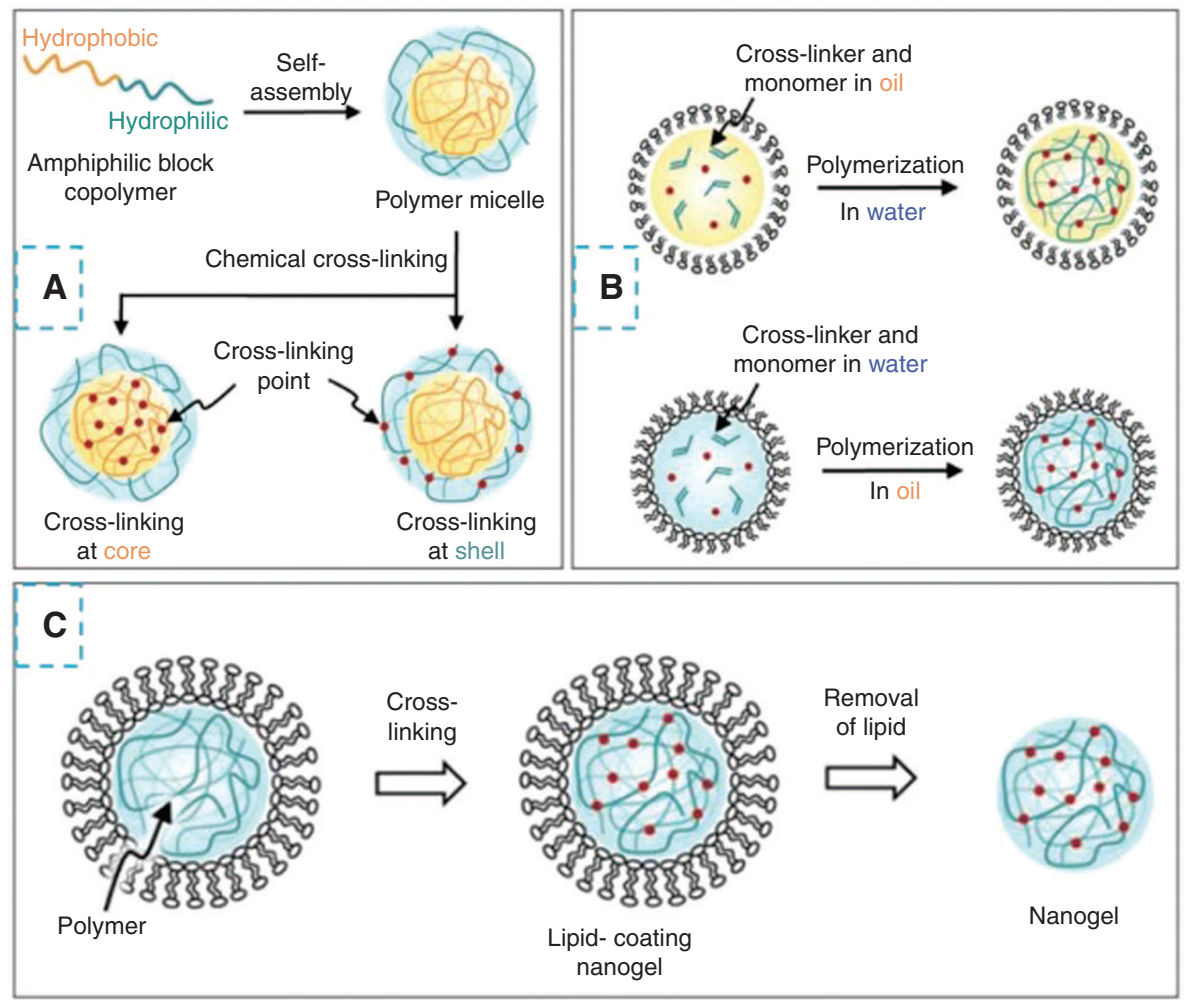

Figure 9: The chemically prepared nanogel by: (A) Crosslinking of amphiphilic block copolymer at core or shell of the polymer micelles in water. (B) Emulsion polymerization with/without emulsion. (C) Using liposome as a template. Adapted from Ref. [5], Copyright (2010) with permission from John Wiley \& Sons, Inc.

C

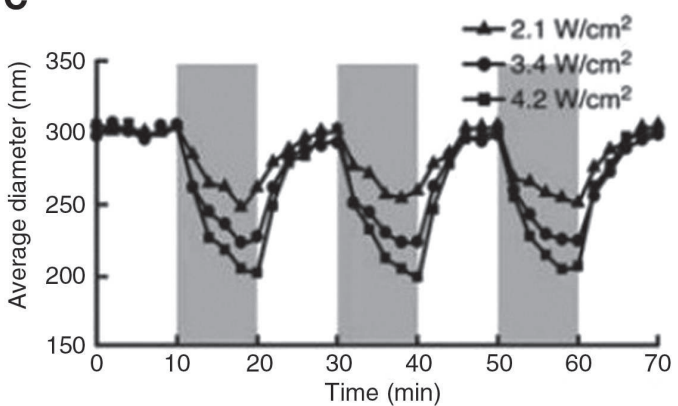

A

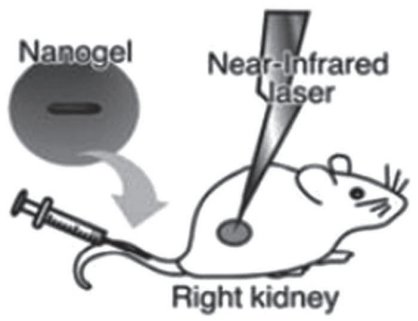

B

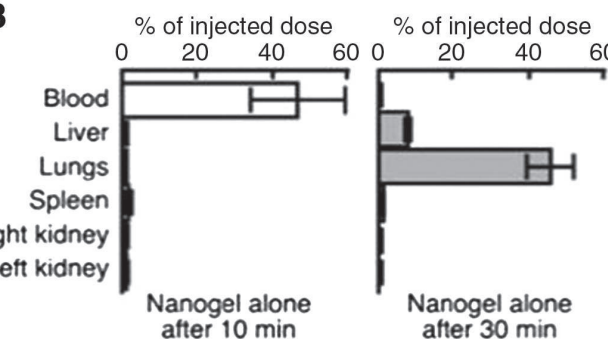

$\%$ of injected dose $\%$ of injected dose
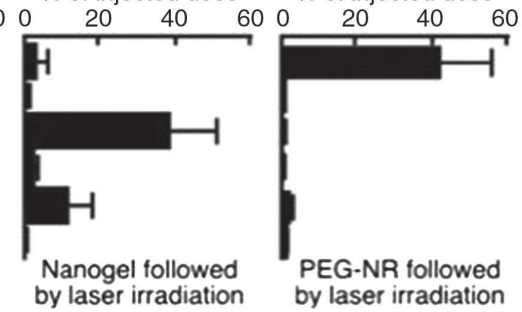

Figure 10: (A) A scheme showing the administration of the gold-hydrogel particle nanocomposites followed by near-IR light irradiation. (B) White and light-gray bars indicate the distribution after 10 and $30 \mathrm{~min}$, respectively, when particle nanocomposites were injected with no irradiation. The black bars indicate the distribution when nanocomposites are injected followed by laser irradiation. The last diagram indicates the injection of polyethylene glycol (PEG)-modified gold nanorods and laser irradiation. (C) The hydrodynamic diameters of PNIPAAm-coated gold nanorods upon irradiation using a near-IR laser with increasing power density. The periods of laser irradiation are indicated by the gray area. Reproduced from Ref. [25] with the permission of The Royal Society of Chemistry. 
- A complex combination of ionic, Van der Waals and hydrogen bonding between the ceramic surface and the electrostatic charges at the minor banding sites of collagen; and

- The epitaxial crystal growth between HA bone mineral crystals and the biomaterial substrate.

\subsection{Hydroxyapatite}

Hydroxyapatite is a mineral found in teeth and bones. It is mainly used as a filler for amputated bone substitution or as a coating for implants for bone ingrowth promotion. However, they have some drawbacks, such as a low bioresorption rate in vivo, a poor stimulating effect on the growth of new bone tissues, low crack resistance and small fatigue durability in the physiological environment. One approach to overcome these drawbacks is to modify the hydroxyapatite structure with uorine or silicon. The biodegradation properties, protein adsorption and adhesion of the coating to the metal substrate can be improved by using uorine [27].

Cell-laden protein-based hydrogels are potentially used in regenerative medicine and soft tissue engineering. Some studies tried to improve the poor mechanical strength of protein-based hydrogels and made them suitable for hard tissue engineering as well. For example, by incorporating nHA into gelatin-based hydrogels, the stiffness of hydrogel significantly improved while the structural integrity and swelling ratio did not change considerably. New minerals with a near-spherical shape also formed homogeneously on the surface of nanocomposites after incubation in simulated body fluid (SBF). Due to the shape of the minerals, they are assumed to be calcium apatite (Figure 11). Moreover, the embedded cells easily extended, proliferated and unified with adjacent cells in the nanocomposite. Thus, it can be said that nHA not only acts as a reinforcing filler, but also stimulates cellular growth and provides a bioactive character for the hydrogel nanocomposite [28].

A recent study demonstrated the fabrication of nanocomposite microspheres based on chitosan, gelatin and nHA. Results indicate that, by changing the nHA/biopolymer (chitosan/gelatin) weight ratio, stirring rate and biopolymer concentration, the particle size and morphology of nanocomposite microspheres would be influenced. Morphological tests indicate that it is possible to fabricate microspheres in wide ranges of particle sizes and different morphologies - from a dense one for drug delivery systems to a porous one for cell delivery applications $[29,30] . \mathrm{NH}_{2}$ content and crosslinking density of such composites based on chitosan/gelatin/nHA can also have great impacts on their performance and mechanical stability in aqueous media [31].

\subsection{Synthetic silicate nanoparticles (nanoclays)}

Mixing linear and branched polymers with nanoclays leads to tissue-adhesive nanocomposite hydrogels with improved mechanical properties [32]. Nanoclay morphology is anisotropic and plate-like with a high aspect-ratio, resulting in high surface interactions. The polymer chains reversibly adsorb and desorb on the silicate surfaces due to the non-covalent interactions between the polymers and the nanoparticles (Figure 12) [33, 34].

Depending on the clay type, the individual layers could be composed of two, three or four sheets of either $\mathrm{SiO}_{4}{ }^{4-}$ tetrahedra or $\left[\mathrm{AlO}_{3}(\mathrm{OH})_{3}\right]^{6}$ octahedra. These layers can organize themselves over one another like pages of a book, with a regular Van der Waals gap between them, called an "interlayer". This interlayer possesses net negative charge, which is due to the ionic substitutions in the sheets of clay minerals. The layer charge is neutralized
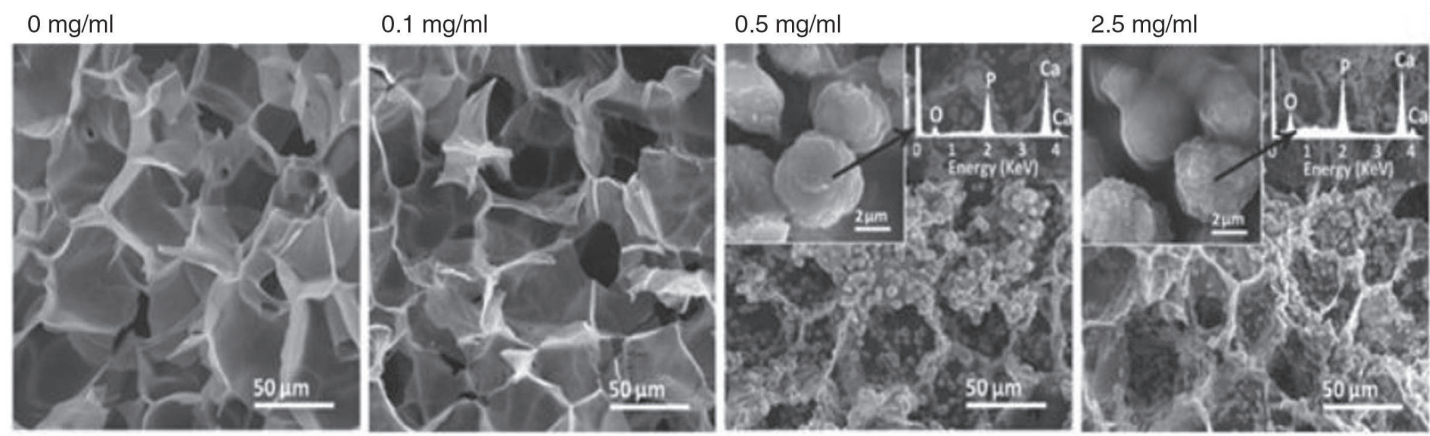

Figure 11: The SEM cross-sectional micrographs of hydrogel/HA nanocomposites containing different concentrations of HA nanoparticles after 30 days of incubation in SBF at $37^{\circ} \mathrm{C}$. Reprinted from Ref. [28], Copyright (2015) with permission from Elsevier. 

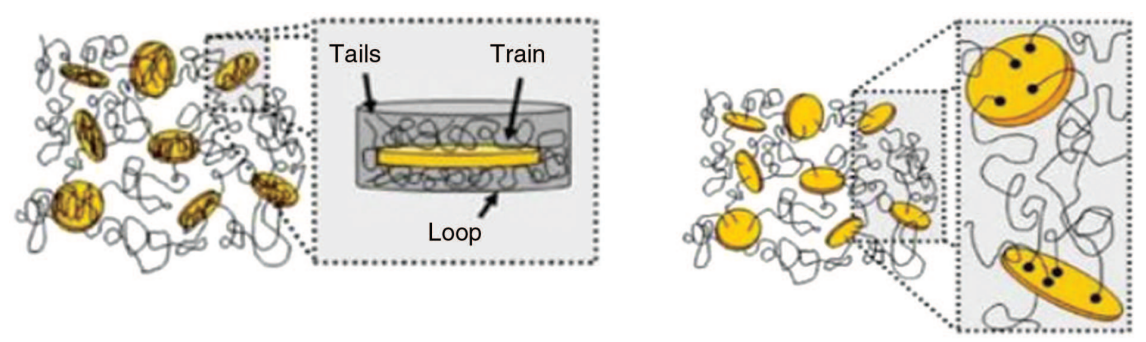

Figure 12: The polymer chains crosslinked with the nanosilicate particles. Ref. [34], (๔ Springer-Verlag 2008) "with permission of Springer".
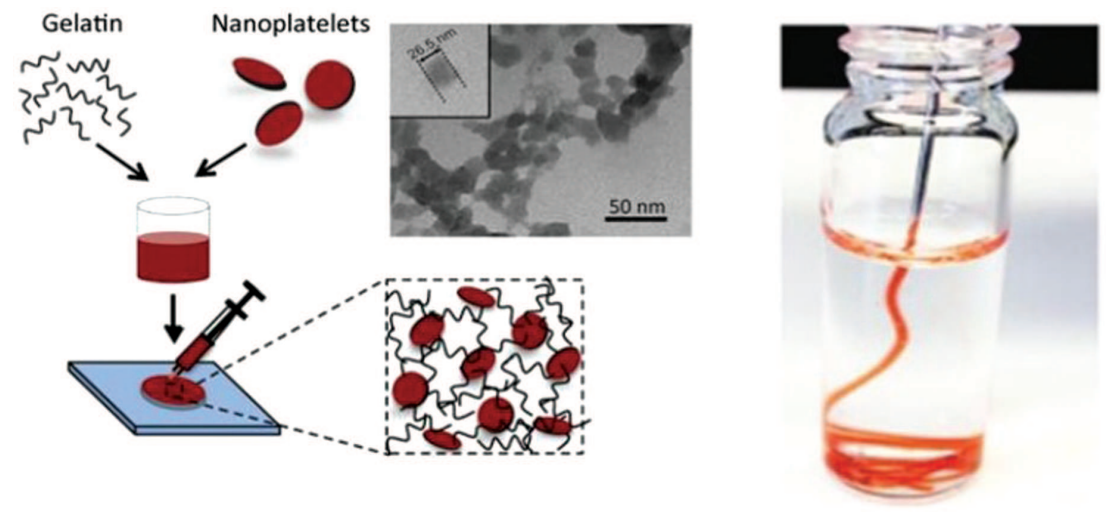

Figure 13: The scheme showing the preparation of the nanocomposite gels and injection of nanocomposite hydrogel through a surgical needle. The TEM image shows the size of the silicate nanoparticle. This is an unofficial adaptation of Ref. [38] that appeared in an ACS publication. ACS has not endorsed the content of this adaptation or the context of its use.

by cations occupying the inter-lamellar and can be easily replaced by other required cations or molecules [35].

Montmorillonite nanolayers have been exfoliated in the chitosan sulfate (SMMT) matrix, presenting a nanohybrid membrane for wounds with low to moderate exudates. These novel wound dressings showed improved physicochemical properties than conventional nanocomposite films. They did not show any cytotoxicity against fibroblast cells and a better cell attachment was observed on Chitosan/SMMT [36].

A type of bio-modified clay, chitosan-intercalated montmorillonite (chitoMMT), has been incorporated into novel hydrogels and compared with the clay-free ones. An electroresponsive polymer served as the hydrogel base and ChitoMMT is embedded within the network to achieve super-swelling nanocomposite. ChitoMMT exhibited no cytotoxicity and enhanced the gel strength and thermal stability at the optimized content of $6 \%$ [37].

Highly charged nanoparticles can localize clotting factors. By concentrating clotting factors, blood coagulation could be induced. Nanoclays are positive along the edge and negative on the top and bottom surfaces. Hence, these charged disks can form self-assembled structures that can dynamically form and break. According to shear-thinning specifications of such systems in aqueous media, they could be used for minimally invasive therapies (Figure 13) $[2,38]$.

One approach for hemorrhage treatment is to engineer into a wound site some injectable biomaterials, which flow with minimal applied pressure during injection, thus avoiding additional patient trauma. The material should solidify quickly and remain at the wound site. To avoid biomaterial loss or flow to unwanted areas, it should be thermally stable. One way to achieve this is to add nanoclays into the gelatin, which would significantly improve the physiological stability, injectability, hemostatic performance and nanocomposite-clot strength. The human blood initiates coagulation in 5-6 $\mathrm{min}$ in normal conditions. The incorporation of nanoclays into gelatin leads to a decrease in the observed clotting time in vitro (Figure 14) [38].

Recent studies have shown that nanoclay can induce the osteogenic differentiation of human mesenchymal stem cells (hMSCs) without the use of exogenous growth factors [39]. For example, poly(glycerol sebacate) (PGS), a widely used material in tissue engineering applications 


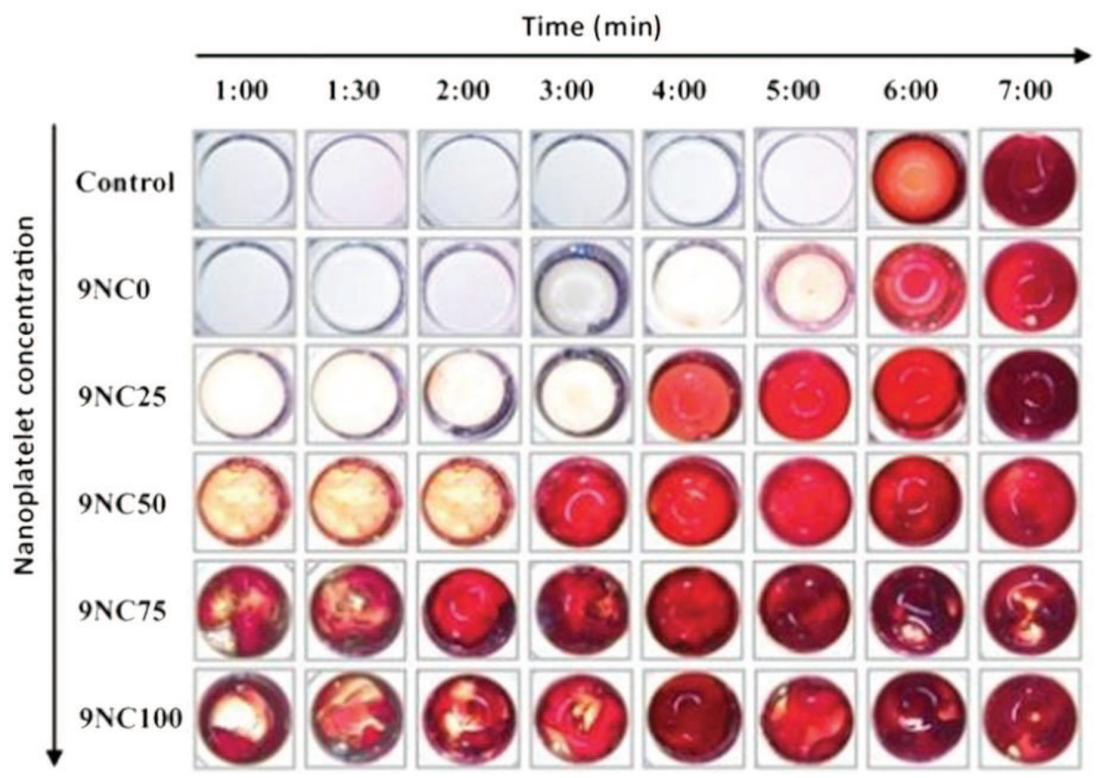

Figure 14: The clot formation as a function of time and nanocomposite composition. xNCy ("x" represents the total solid weight percent and " $y$ " is percent of the total solid weight percent that is nanoplatelet). This is an unofficial adaptation of Ref. [38] that appeared in an ACS publication. ACS has not endorsed the content of this adaptation or the context of its use.

A<smiles>O=C(O)CCCCCCC(=O)O</smiles>

B
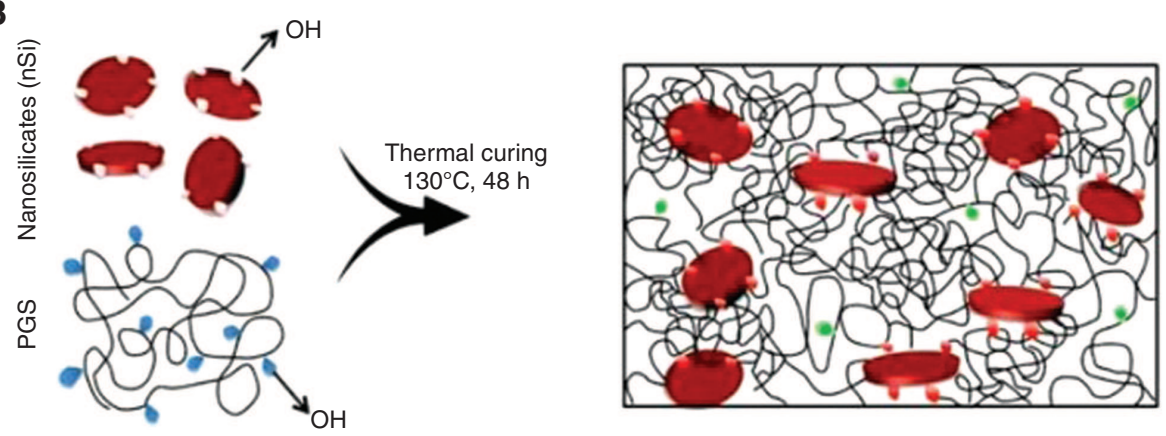

Figure 15: (A) Chemical structure of PGS. (B) Interactions between PGS chains and nanosilicates. Reprinted from Ref. [40], Copyright (2015), with permission from Elsevier.

because of its tough elastomeric mechanical properties, biocompatibility and controllable degradation, lacks enough bioactivity and has limited utilization for musculoskeletal tissue engineering. By covalently reinforcing the PGS network with 2D nanoclays, a bioactive highly elastomeric and mechanically stiff nanocomposite is obtained, while also significantly enhancing cell adhesion and proliferation (Figures 15 and 16). The in vitro stability of nanocomposites is also better with the higher amount of nanosilicates [40]. However, the long-term cytotoxicity of silicate nanoparticles must be investigated through further in vivo experiments.

\subsection{Glass ceramics}

Glass is an inorganic, amorphous material with a randomly arranged atomic structure [41]. It is possible to rearrange the random structure of glass to an ordered structure 

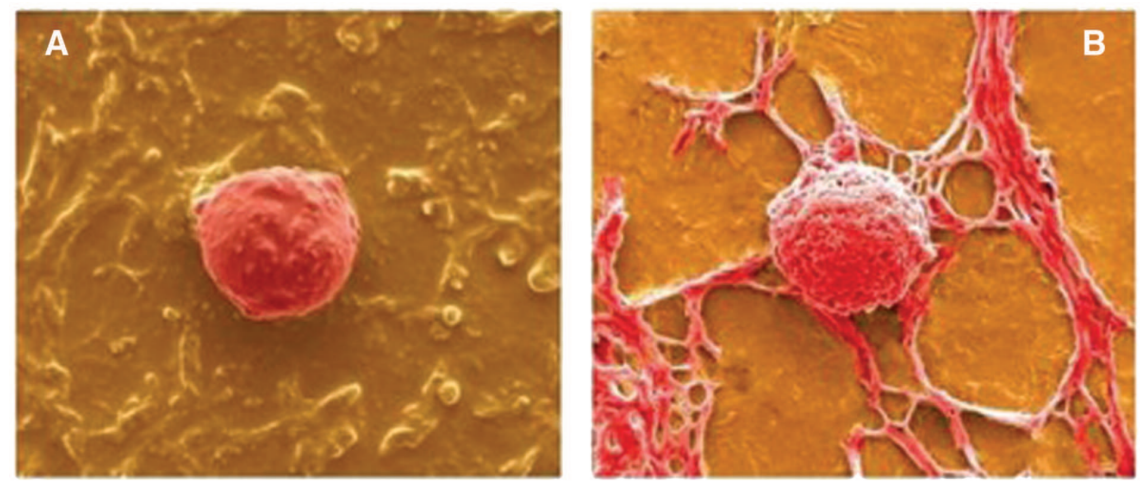

Figure 16: (A) PGS (B) PGS-Nanosilicate. Reprinted from Ref. [40], Copyright (2015), with permission from Elsevier.

A

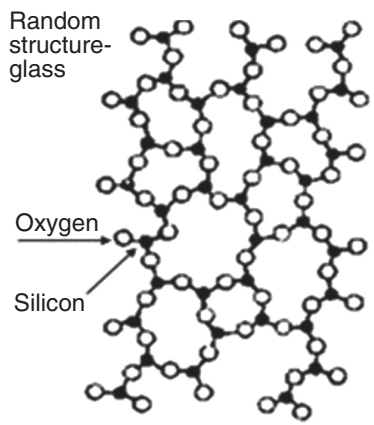

B

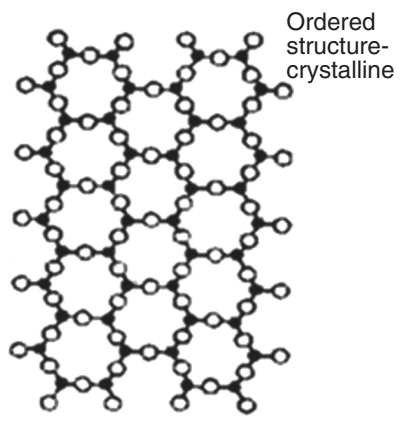

Figure 17: The structural difference between a glass and a ceramic; (A) Silica glass random structure (B) Quartz (crystallized silica) ordered structure. Image available at Ref. [41].

of a ceramic, which is more stable than others (Figure 17). The result is called a glass-ceramic.

Bioactive glasses are a group of surface reactive glassceramic biomaterials. These can be integrated in polymeric hydrogels as reinforcing bone growth induction agents in order to obtain nanocomposite hydrogels. A commercially available family of bioactive glasses, called bioglass, comprises $\mathrm{SiO}_{2}, \mathrm{Na}_{2} \mathrm{O}, \mathrm{CaO}$ and $\mathrm{P}_{2} \mathrm{O}_{5}$ in specific proportions. The formation of apatite crystals is due to the high ratio of calcium to phosphorus. Meanwhile, calcium and silica ions act as crystallization core. These biocompatible glasses are extensively used as implant materials to repair and replace damaged bone (Figure 18) [42]. Recent studies focused on the modification of bioactive glass surface. The surface morphology is a key component in defining the bioactive response [43].

A bioactive glass transforms to hydroxyapatite crystals and immerses in a physiological environment in five stages. First, $\mathrm{Na}^{+}$cations in the glass network exchange with hydronium ions in the external solution (ion exchange stage). Second, the Si-O-Si molecules breaks into $\mathrm{Si}-\mathrm{OH}$ silanol groups and the glass network

is disrupted (hydrolysis stage). The silanol groups of previous stage condensate and form a gel-like layer (condensation stage); then, an amorphous calcium phosphate layer is deposited on this gel layer (precipitation stage). Finally, the calcium phosphate layer gradually transforms into crystalline hydroxyapatite (mineralization stage) [43].

\subsection{Calcium phosphate}

Several different forms of calcium phosphate can fulfill different jobs. One type of calcium phosphate is hydroxyapatite, which exists in bones and teeth. Other forms of calcium phosphate are used in food products. However, the use of hydroxyapatite as a food supplement is discouraged [44].

If your diet does not provide a steady supply of calcium, your body can not continuously remove or replace the old or damaged bone with new bone. Calcium phosphate contains a smaller amount of calcium than other types of common and economical supplementations for calcium, like calcium carbonate and calcium citrate. However, dicalcium and tricalcium phosphates have higher amounts of calcium. Tricalcium phosphate has about the same amount of calcium per dose as calcium carbonate, and it is used as a nutritional supplement naturally found in cow milk $[44,45]$. Hence, the nanoparticles of calcium phosphate embedded within hydrogels can be a good choice for stimulating bone growth.

\subsection{Wollastonite}

Wollastonite $\left(\mathrm{CaSiO}_{3}\right)$ is a calcium silicate that has been used as a filler to improve the mechanical properties of different composites. It has good bioactivity and biocompatibility, which makes it a potential material for artificial bones and dental roots [46]. In vitro experiments show that a hyroxyapatite surface layer with $\mathrm{pH}$, temperature and 

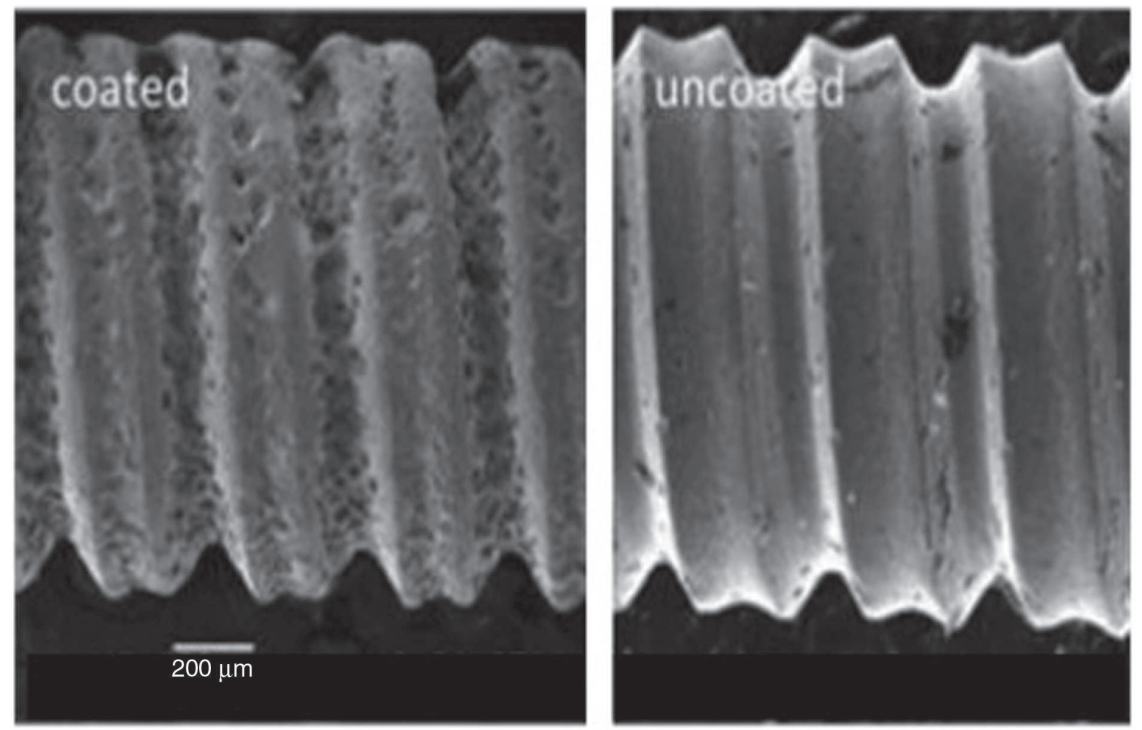

Figure 18: The bioactive glass coating on a Ti6Al4V (6\% Aluminium, $4 \%$ Vanadium, $0.25 \%$ (maximum) Iron, $0.2 \%$ (maximum) 0xygen and the remainder Titanium) implant screw. Image available at Ref. [42].

ion concentration of human blood plasma is formed upon the exposure of wollastonite to SBF. This finding opens up a wide field for applications of wollastonite as an artificial material that can be used as bioactive bone substitute. Reinforced nanocomposite hydrogels can be obtained by combining these inorganic bioactive nanoparticles with natural or synthetic polymeric hydrogels [47].

\section{Metallic-based nanocomposite hydrogels}

Different metallic nanoparticles can be used to create nanocomposite hydrogels for biomedical applications, including as gold $(\mathrm{Au})$, silver $(\mathrm{Ag})$ and metal-oxide nanoparticles, such as iron oxide $\left(\mathrm{Fe}_{3} \mathrm{O}_{4}, \mathrm{Fe}_{2} \mathrm{O}_{3}\right)$, titania $\left(\mathrm{TiO}_{2}\right)$, alumina and zirconia, among others [34].

The metallic nanoparticles show eligible physical properties, such as electrical and thermal conductivity (Au nanorods), magnetic properties (iron oxides) and antimicrobial properties (Ag nanoparticles). Therefore, nanocomposite hydrogels comprising metal or metaloxide nanoparticles are widely used as imaging agents or in drug-delivery systems, conductive scaffolds, switchable electronics, actuators, and sensors [2, 34].

By modifying the nanoparticle surfaces with functional groups, the weak interactions between the polymer chains and the metallic nanoparticles can be enhanced [48]. Alumina and titania nanoparticles have limited use in fabricating hydrogel structures due to their limited interactions with polymeric chains, and no enhancement in the physical properties of the hydrogel network has been reported [2].

\subsection{Anti-microbial effect of metallic nanoparticles}

Metals like copper and silver can be used as antimicrobial agents, because they are toxic to bacteria and are also stable under physiological conditions. Polymer/metal nanocomposites can also be made by several routes, such as the in situ synthesis of the nanoparticle within a hydrogel or the direct addition of the metal nanofiller into a hydrogel matrix. This can extend the antimicrobial application of these metals.

The antimicrobial mechanism of these nanocomposites is based on the steps explaining how bacteria disappear in the physiological environment. As shown in Figure 19, the bacteria absorbed on the polymer surface and water with dissolved oxygen diffuse to the polymer matrix from the surrounding medium. Oxygen molecules reach the surface and the corrosion process with the embedded metal nanoparticles occurs. Metal ions are released and reach the composite surface, thus causing damage to the bacteria membrane and are eventually diffused into the bacteria [49].

Silver nanoparticles are non-toxic antibacterial agents with a poor binding affinity with surfaces. The nucleation and growth of these nanoparticles can occur in free spaces between the crosslinked networks of hydrogels in the swollen position. In fact, these spaces act as a nanoreactor. Recent advances aim to obtain silver nanoparticles 


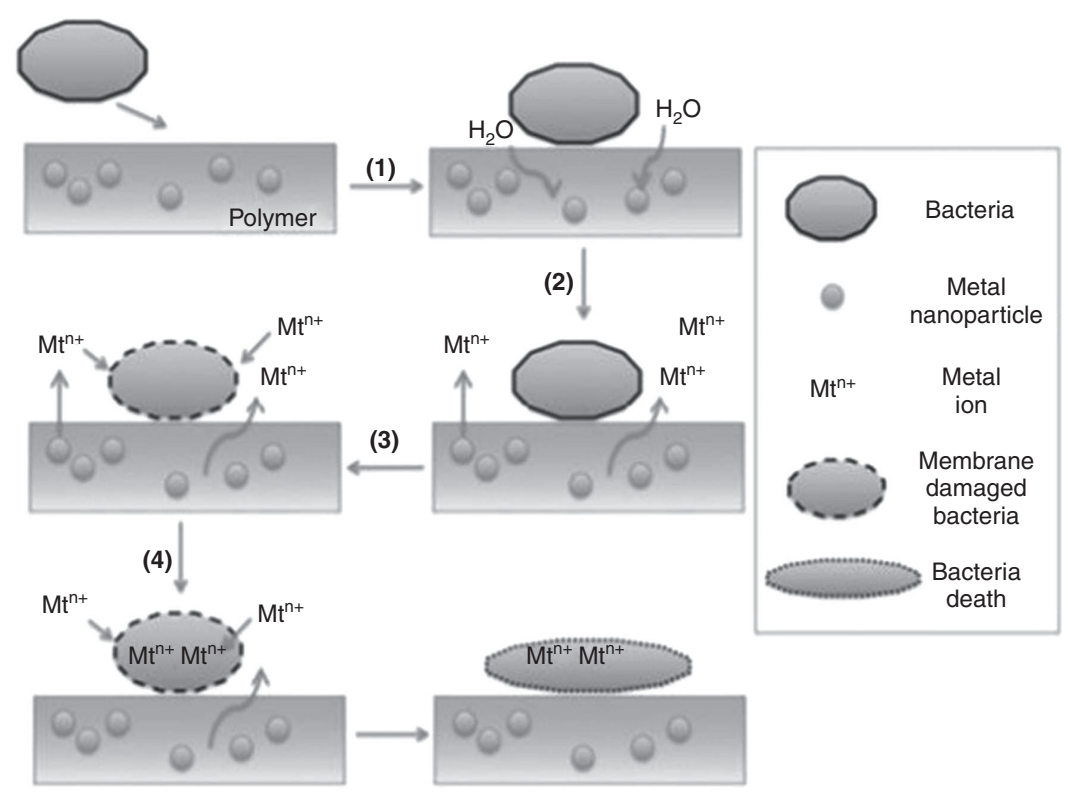

Figure 19: The antimicrobial mechanism of polymer/metal nanocomposites. Adapted from Ref. [49], Copyright (2015), distributed under the terms of the Creative Commons Attribution license.

in gel networks (Figure 20). Silver nanoparticle size can also influence the antibacterial activity of the hydrogel nanocomposite. The results of the antibacterial activity test towards $E$. Coli shows that the lower size nanoparticles have better antibacterial activity, because they could come out of the hydrogel network easily and interact with $E$. Coli (Figure 21). Even if the silver nanoparticles can leave the hydrogel network, they do not show a high antibacterial activity, especially if the size is large [50].

\subsection{Magnetic nanoparticles}

The magnetic nanoparticles embedded within a hydrogel network generate heat when subjected to external magnetic fields. Therefore, the temperature of the surrounding matrix reaches above the lower critical solution temperature (LCST) of the polymer and results in a coil-to-globule transition of the polymer chains (Figure 22). Hence, the therapeutic agents or cells embedded within the hydrogel network are released [25]. The magnetic-based nanocomposite hydrogels can remotely interact with the exterior magnetic fields and can thus be used for biosensing, diagnostic and bioactuation applications [2, 51].

For the fabrication of monodispersed core-shell hybrid particles with a magnetic core and a biocompatible polymeric shell, the magnetic nanoparticles are fabricated through the co-precipitation technique. Particle surface iss modified with the amine functional groups of (3-aminopropyl) trimethoxysilane (APTMS). Finally, the hydroxypropyle cellulose (HPC), a thermoresponsive polymer, is covalently joined to the amine groups. This is a unique combination between paramagnetic nature of the particles and the thermoresponsive behavior of the cellulose. Such a hybrid system would be a good remote-controlled drug carrier [51].

By seeding the heart cells within 3D porous scaffolds made from biological or synthetic polymers like alginate or poly lactic acid (PLA), the engineered cardiac patches are produced. Thus, the cells inside the scaffold gradually organize into functioning tissues. However, the patch cannot act strongly as a unit due to the poor conductivity of these materials [52].

In an interesting application, gold nanowires are incorporated within alginate scaffolds for treating damaged heart tissues. Alginate is selected because of its extensive use in myocardial regeneration. The electrically resistant pore walls of alginate can be connected through gold nanowires acting as a bridge between cardiac cells. In order to connect with cells on both sides, nanowires must be longer than the average thickness of the alginate pore wall (Figure 23). Compared to pristine alginate, tissues grown on these matrices are thicker and better unified. In addition, the cells contract synchronously when stimulated electrically. Moreover, the resulting nanocomposites have improved the mechanical properties because the nanowires can act as reinforcing agents [52].

Table 1 shows some important recent works in the field of nanocomposite hydrogels considering the carbonic, polymeric, inorganic and metallic nanoparticle categorization made in this review. 
Table 1: Some important works in the field of nanocomposite hydrogels (NCHs) in the last 5 year.

\begin{tabular}{|c|c|c|c|c|}
\hline Experts (year) & $\begin{array}{l}\text { Type of } \\
\text { nanoparticle }\end{array}$ & Main features & Method & Application \\
\hline $\begin{array}{l}\text { Tomas et al. } \\
\text { [53] (2017) }\end{array}$ & Inorganic & $\begin{array}{l}\text { - Highlighted the potentials of - } \\
\text { - Laponite } \\
\text { - High aspect ratio } \\
\text { - Interacts with chemical entities } \\
\text { - Easily functionalized } \\
\text { - Readily degraded in the body }\end{array}$ & - & $\begin{array}{l}\text { Drug delivery } \\
\text { Bioimaging } \\
\text { Tissue engineering }\end{array}$ \\
\hline $\begin{array}{l}\text { Cinay et al. } \\
\text { [54] (2017) }\end{array}$ & Polymeric & $\begin{array}{l}\text { - Ph-responsive } \\
\text { - Modified cholesterol bearing Pullulan } \\
\text { nanogels incorporated } \\
\text { - An anticonvulsant drug (pregabalin) } \\
\text { was used } \\
\text { - Delivery of drugs with different } \\
\text { hydrophobicities }\end{array}$ & $\begin{array}{l}\text { Visible light-induced } \\
\text { synthesis }\end{array}$ & Drug delivery \\
\hline $\begin{array}{l}\text { Marrella et al. } \\
{[55](2017)}\end{array}$ & Carbonic & $\begin{array}{l}\text { - Alginate-based } \\
\text { - Functionalized with GO } \\
\text { - Timely increase of intermolecular } \\
\text { hydrogen bonds } \\
\text { - } 300 \text { kpa compressive elastic modulus }\end{array}$ & Chemical crosslinking & Articular tissues \\
\hline $\begin{array}{l}\text { Jaiswal et al. } \\
\text { [56] (2017) }\end{array}$ & Metallic & $\begin{array}{l}\text { - Mechanically resilient } \\
\text { - Elastomeric }\end{array}$ & $\begin{array}{l}\text { Vacancy-driven gelation } \\
\text { using defect-rich 2D } \\
\text { transition metal } \\
\text { dichalcogenides }\left(\mathrm{MoS}_{2}\right)\end{array}$ & Tissue engineering \\
\hline $\begin{array}{l}\text { Liang et al. } \\
\text { [57] (2016) }\end{array}$ & Polymeric & $\begin{array}{l}\text { - Liposome-cross-linked } \\
\text { - Maleimide-functionalized cross-linkers } \\
\text { - Novel chemical degradation }\end{array}$ & $\begin{array}{l}\text { Michael-type addition of } \\
\text { thiols }\end{array}$ & Drug delivery \\
\hline $\begin{array}{l}\text { Ji et al. [58] } \\
(2016)\end{array}$ & Carbonic & $\begin{array}{l}\text { - Highlighted the mechanisms of } \\
\text { antibacterial activity in graphene-based } \\
\text { materials } \\
\text { - Direct contact of sharp edges with } \\
\text { bacterial membranes } \\
\text { - Wrapping } \\
\text { - Photothermal ablation }\end{array}$ & - & $\begin{array}{l}\text { Antibacterial } \\
\text { packaging } \\
\text { Wound dressing }\end{array}$ \\
\hline $\begin{array}{l}\text { Pathania et al. } \\
\text { [59] (2016) }\end{array}$ & Metallic & $\begin{array}{l}\text { - Chitosan-g-poly(acrylamide)/Zn } \\
\text { - Drug: ofloxacin } \\
\text { - Ph-dependent drug release } \\
\text { - Antibacterial against } E \text {. Coli. }\end{array}$ & $\begin{array}{l}\text { Grafting in the presence of } \\
\text { microwave radations }\end{array}$ & Drug delivery \\
\hline $\begin{array}{l}\text { Moghadas et } \\
\text { al. [36] (2016) }\end{array}$ & Inorganic & $\begin{array}{l}\text { - Chitosan/montmorillonite (MMT)-based } \\
\text { films } \\
\text { - Improved tensile strength } \\
\text { - Improved Yang's modulus } \\
\text { - Improved thermal stability } \\
\text { - Low moisture vapor transmission rate }\end{array}$ & $\begin{array}{l}\text { Biofunctionalization of } \\
\text { nanoparticle (MMT) }\end{array}$ & Wound dressing \\
\hline $\begin{array}{l}\text { Sadat-Shojai } \\
\text { et al. [28] } \\
(2015)\end{array}$ & Inorganic & $\begin{array}{l}\text { - Gelatin-based } \\
\text { - Nanohydroxyapatite incorporated } \\
\text { - 3D mineralization } \\
\text { - 3D cellular growth } \\
\text { - Improved stiffness } \\
\text { - Maintained structural integrity } \\
\text { - Maintained swelling ratio }\end{array}$ & $\begin{array}{l}\text { Exposure of } \\
\text { solution/dispersion to UV } \\
\text { light }\end{array}$ & $\begin{array}{l}\text { Hard tissue } \\
\text { engineering }\end{array}$ \\
\hline
\end{tabular}


Table 1 (continued)

\begin{tabular}{|c|c|c|c|c|}
\hline Experts (year) & Type of nanoparticle & Main features & Method & Application \\
\hline $\begin{array}{l}\text { Brunetti et al. } \\
{[60](2015)}\end{array}$ & Polymeric & $\begin{array}{l}\text { - Nanoparticle-cored dendrimers } \\
\text { compared with non-dendritic stabilized } \\
\text { nanoparticles }\end{array}$ & - & Drug delivery \\
\hline $\begin{array}{l}\text { Gaharwar et } \\
\text { al. [8] (2015) }\end{array}$ & Carbonic & $\begin{array}{l}\text { - PGS-based } \\
\text { - CNTS as both physical and covalent } \\
\text { crosslinker } \\
\text { - Efficient non-reversible crosslinking }\end{array}$ & $\begin{array}{l}\mathrm{COOH} \text {-functionalization of } \\
\text { nanoparticle (CNT) }\end{array}$ & $\begin{array}{l}\text { Musculoskeletal } \\
\text { tissue engineering }\end{array}$ \\
\hline $\begin{array}{l}\text { Palza et al. } \\
\text { [49] (2015) }\end{array}$ & Metallic & $\begin{array}{l}\text { - Routes of fabricating Metal/polymer } \\
\text { NCHS: } \\
\text { - In situ synthesis of the metal } \\
\text { nanoparticles within a hydrogel } \\
\text { - Direct addition of the metal nanofiller } \\
\text { into a thermoplastic matrix }\end{array}$ & - & $\begin{array}{l}\text { Antibacterial drug } \\
\text { carriers }\end{array}$ \\
\hline $\begin{array}{l}\text { Zhao et al. } \\
\text { [61] (2015) }\end{array}$ & Metallic & $\begin{array}{l}\text { - Hemicellulose-based } \\
\text { - Magnetic field responsive } \\
\text { - Combining the renewability of } \\
\text { hemicellulose and the magnetism of } \\
\mathrm{Fe}_{3} \mathrm{O}_{4}\end{array}$ & $\begin{array}{l}\text { A straight-forward one-step } \\
\text { process }\end{array}$ & Drug delivery \\
\hline $\begin{array}{l}\text { Gaharwar et } \\
\text { al. [38] (2014) }\end{array}$ & Inorganic & $\begin{array}{l}\text { - Gelatin-based } \\
\text { - Nanoclays incorporated } \\
\text { - Injectable } \\
\text { - Shear thinning effect } \\
\text { - Decreased blood clotting times } \\
\text { - Forms stable clot-gel systems }\end{array}$ & $\begin{array}{l}\text { Vortexing the gelatin stock } \\
\text { and nanoplatelet stock at } \\
3000 \mathrm{rpm}\end{array}$ & $\begin{array}{l}\text { Hemostatic agents } \\
\text { for emergency } \\
\text { conditions }\end{array}$ \\
\hline $\begin{array}{l}\text { Lopez- } \\
\text { Noriega et al. } \\
\text { [62] (2014) }\end{array}$ & Polymeric & $\begin{array}{l}\text { - Chitosan-based } \\
\text { - Injectable } \\
\text { - Containing doxorubicin-loaded } \\
\text { thermosensitive liposomes }\end{array}$ & $\begin{array}{l}\text { In situ gelation of } \\
\text { thermoresponsive hydrogel }\end{array}$ & Drug delivery \\
\hline $\begin{array}{l}\text { Paul et al. [9] } \\
(2014)\end{array}$ & Carbonic & $\begin{array}{l}\text { - Injectable } \\
\text { - Functionalized go and a growth factor } \\
\text { incorporated } \\
\text { - No significant differences in cytotoxicity } \\
\text { compared to non-go groups } \\
\text { - Site-specific gene therapy }\end{array}$ & $\begin{array}{l}\text { PEI-functionalization of } \\
\text { nanostructure (GO) }\end{array}$ & $\begin{array}{l}\text { Myocardial gene } \\
\text { therapy }\end{array}$ \\
\hline $\begin{array}{l}\text { Zhang et al. } \\
\text { [63] (2014) }\end{array}$ & Inorganic & $\begin{array}{l}\text { - Physical crosslinkers (Lithium } \\
\text { magnesium silicate hydrate and silk } \\
\text { sericin) } \\
\text { - Improved cell compatibility } \\
\text { - Improved fragility } \\
\text { - Bigger volume and rapid } \\
\text { thermo-responsibility }\end{array}$ & Physical crosslinking & Tissue engineering \\
\hline $\begin{array}{l}\text { Gaharwar et } \\
\text { al. [39] (2013) }\end{array}$ & Inorganic & $\begin{array}{l}\text { Demonstrated that: } \\
\text { - Synthetic silicate nanoplatelets alone } \\
\text { can induce the osteogenic } \\
\text { differentiation of human mesenchymal } \\
\text { stem cells in the absence of any } \\
\text { osteogenic factors }\end{array}$ & - & $\begin{array}{l}\text { Bone tissue } \\
\text { engineering }\end{array}$ \\
\hline
\end{tabular}


Table 1 (continued)

\begin{tabular}{|c|c|c|c|c|}
\hline Experts (year) & Type of nanoparticle & Main features & Method & Application \\
\hline $\begin{array}{l}\text { Ramán-Azcón } \\
\text { et al. [64] } \\
\text { (2013) }\end{array}$ & Carbonic & $\begin{array}{l}\text { - Gelatin methacrylate-based } \\
\text { - Higher electrical properties } \\
\text { - Higher maturation of cultured muscle } \\
\text { cells }\end{array}$ & $\begin{array}{l}\text { Dielectrophoresis alignment } \\
\text { of nanostructures (CNTs) }\end{array}$ & $\begin{array}{l}\text { Soft tissue } \\
\text { engineering }\end{array}$ \\
\hline $\begin{array}{l}\text { Zhang et al. } \\
\text { [20] (2013) }\end{array}$ & Polymeric & $\begin{array}{l}\text { - A hyper-branched HPE } \\
\text { - Encapsulate hydrophobic drugs } \\
\text { - Induced cell adhesion and proliferation }\end{array}$ & Photo-crosslinking & Drug delivery \\
\hline $\begin{array}{l}\text { Solouk et al. } \\
\text { [19] (2011) }\end{array}$ & Polymeric & $\begin{array}{l}\text { - Collagen-grafted hydrogel based on } \\
\text { POSS nanoparticles } \\
\text { - Better cell adhesion } \\
\text { - Improved surface properties }\end{array}$ & $\begin{array}{l}\text { Grafting on a plasma-treated } \\
\text { nanocomposite }\end{array}$ & Tissue engineering \\
\hline $\begin{array}{l}\text { Davir et al. } \\
\text { [52] (2011) }\end{array}$ & Metallic & $\begin{array}{l}\text { - } \text { Alginate-based } \\
\text { - Gold nanowires bridge the pore walls of } \\
\text { Alginate } \\
\text { - Improved electrical communication } \\
\text { between cardiac cells } \\
\text { - } \text { Thicker and better aligned tissues }\end{array}$ & $\begin{array}{l}\text { Crosslinking of } \\
\text { alginate/nanowire solution } \\
\text { with a bivalent crosslinker } \\
\text { followed by freezing and } \\
\text { lyophilization }\end{array}$ & Cardiac patches \\
\hline
\end{tabular}
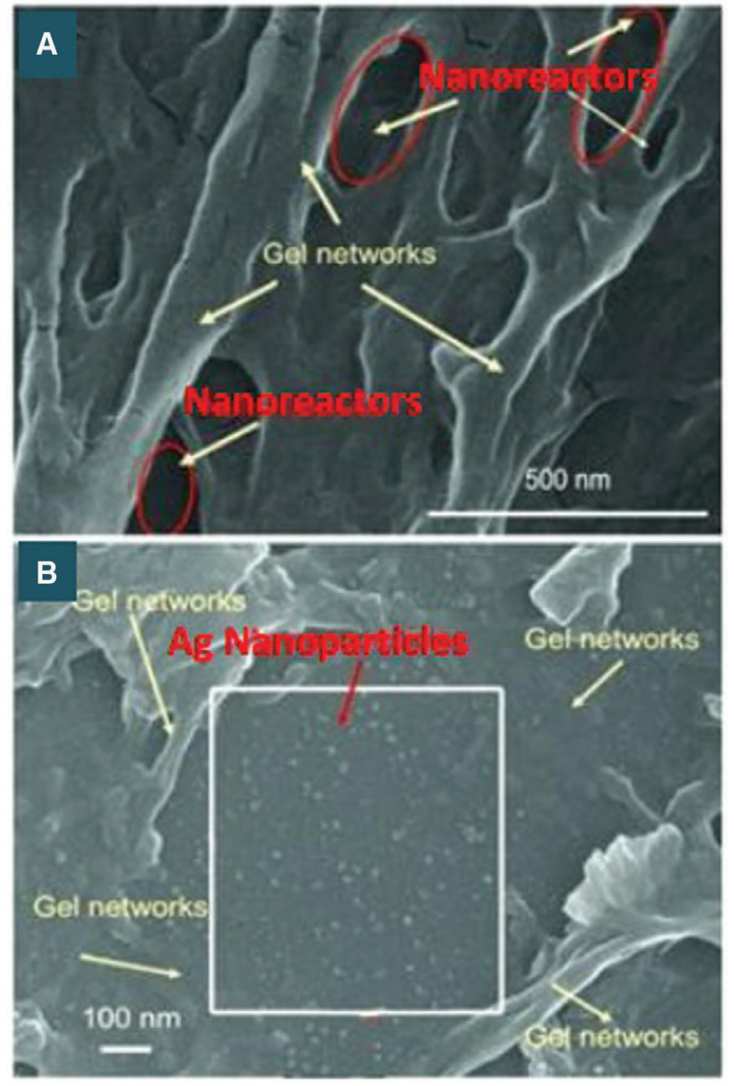

Figure 20: The SEM of (A) Pure hydrogel and (B) silver nanoparticle grown in crosslinked hydrogel network. Reprinted from Ref. [50], Copyright (2006), with permission from Elsevier.

\section{Current trends}

Some essential features must be controlled in the current nanocomposite hydrogels, including stimuli responsiveness, biodegradation and optimized mechanical strength. The kind of stimuli used for changing the properties of the hydrogel is based on the kind of nanoparticles embedded within the hydrogel networks. A range of stimuli-responsive elements can be incorporated within nanocomposite hydrogels, such as mechanically adaptive, $\mathrm{pH} /$ enzyme/ion responsive, electrically stimulating, thermoresponsive and magnetic responsive elements. These are the future directions in development of nanocomposite hydrogels [34].

One trend that could be considered is the multi-phase combination within a nanocomposite hydrogel network to imitate the structure and properties of native tissues. Past studies have reported the superior physical and chemical properties in multi-component hydrogels in comparison with the two-component systems [2]. Further experiments are required to overcome the complexity of optimizing these systems for the required applications.

In the case of synthesized nanoparticles, although various forms of nanoparticles have already been synthesized by using biogenic sources (e.g. plants, bacteria, fungi, yeast, etc.) [1], there are still many types of nanoparticles that have been synthesized based on the physical/chemical methods. However, no study has yet 

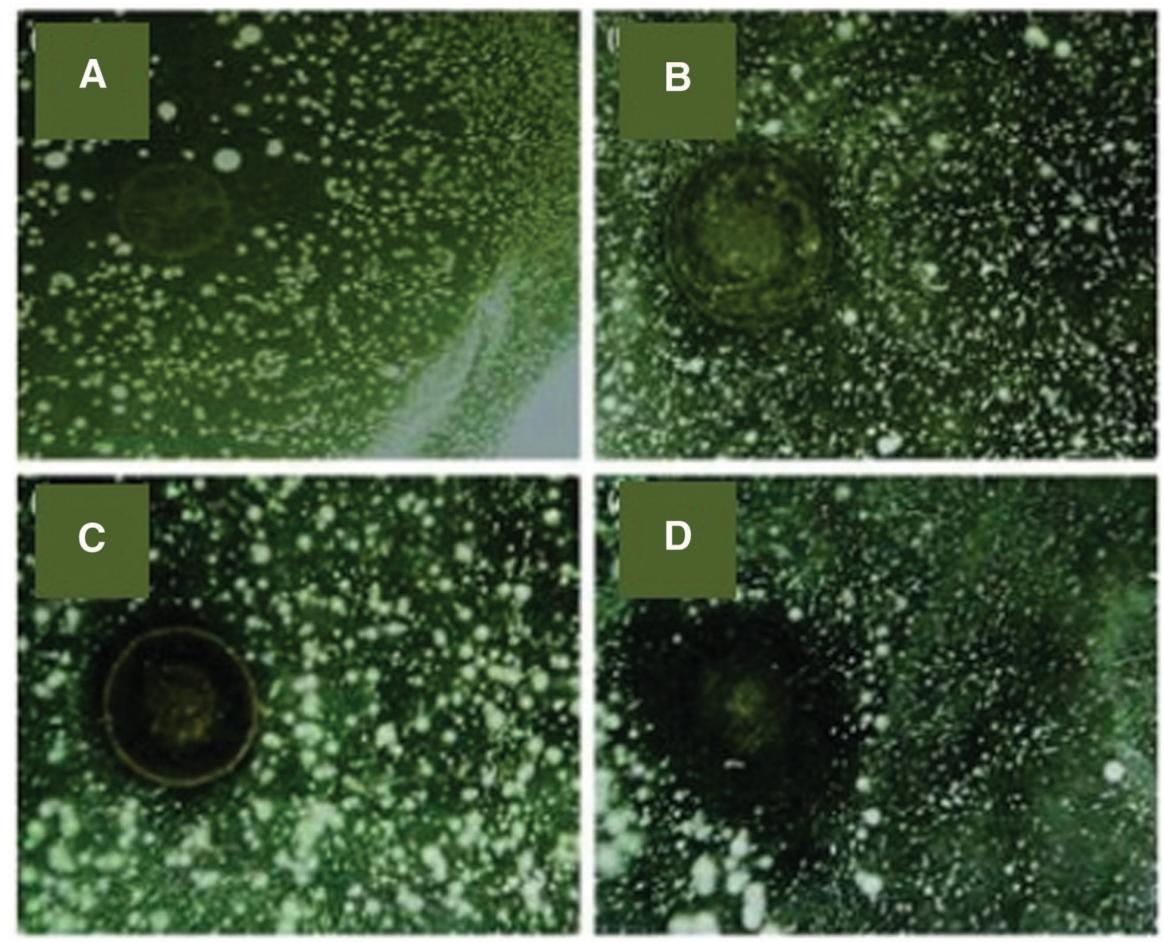

Figure 21: The antibacterial results of the hydrogel/silver nanoparticles; (A-D) dead bacteria zone increases by silver nanoparticle size decrease. Reprinted from Ref. [50], Copyright (2006), with permission from Elsevier.

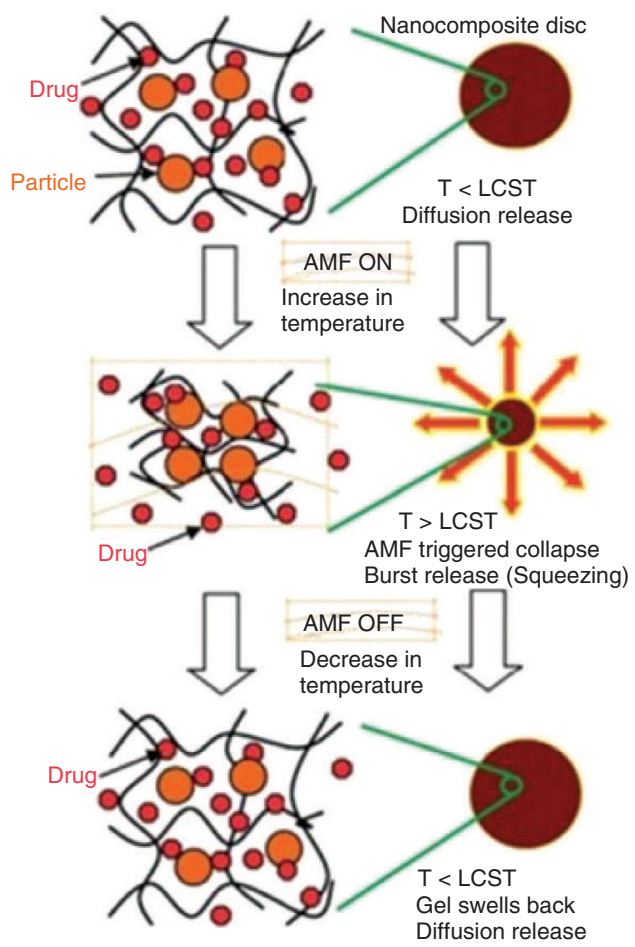

Figure 22: The remote controlled pulsatile drug release from a magnetic hydrogel nanocomposite. A schematic of AMF-induced heating, collapse and squeezing effects. Reproduced from Ref. [25] with the permission of The Royal Society of Chemistry. to investigate the biogenic synthesis of CNTs using an ecofriendly method.

Most of the approaches made to improve the nanoparticle/hydrogel interactions is based on the surface modification of the nanoparticles. On the one hand, covalent functionalization forms stable chemical bonds, but the novel nanoparticle properties may be lost. On the other hand, non-covalent functionalization has limited for drug-delivery applications because it is based on weak Van der Waals forces [1]. Hence there is a need for nondestructive approaches (like non-covalent modifications), which could make stable bonds (like covalent modifications) in the surface modification of the nanoparticles simultaneously and provide the benefits of both covalent and non-covalent functionalization.

In the future, more attention will be paid to other types of technologies, such as microfabrication approaches, to make hybrid materials [2]. The use of microscale technologies will enable us to overcome some of the complexities in engineering functional tissues. Engineering tissues with the spatiotemporal control of cells and biophysical signals is a goal that can be achieved by gaining a better understanding of cell-nanomaterial interactions. Many microfabrication approaches have been proposed to locate different types of cells within the hydrogel network and facilitate effective tissue formation. The development of 

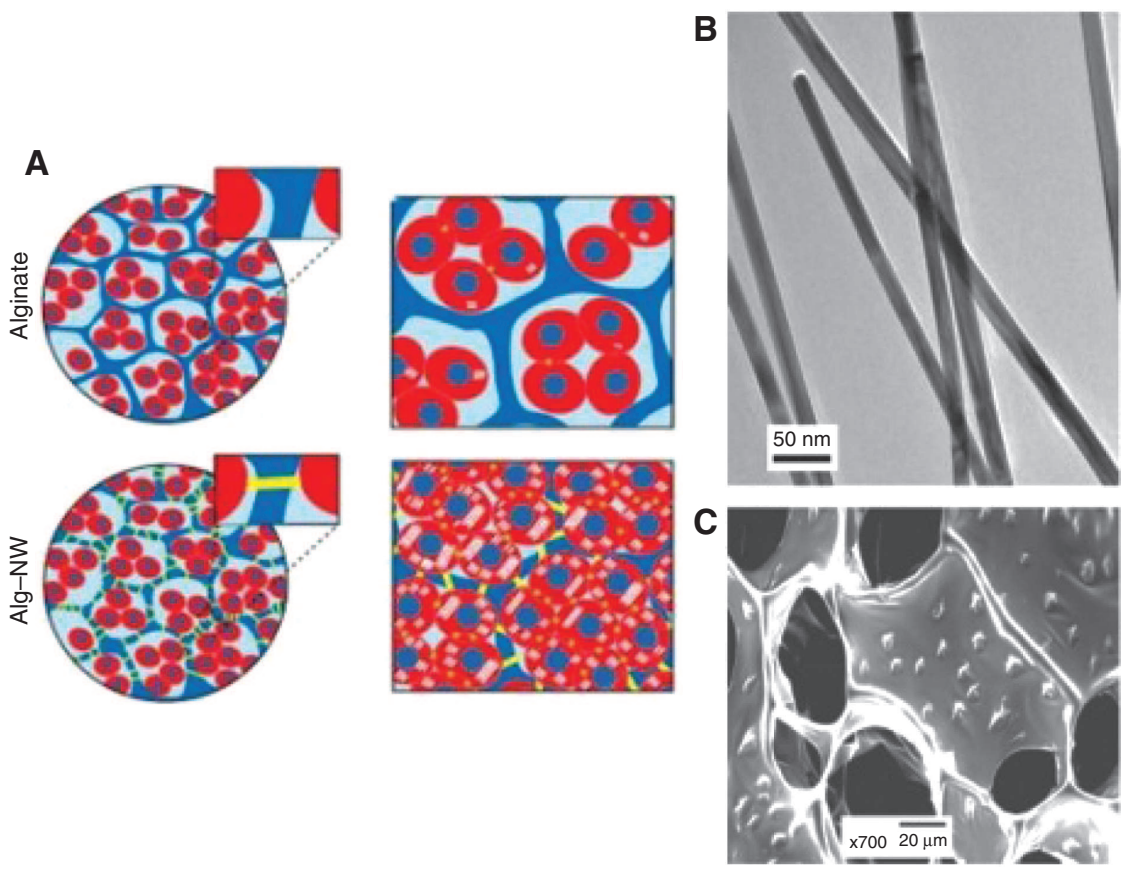

Figure 23: (A) The isolated cardiomyocytes are cultured in either pristine alginate or alginate-nanowire composites; cardiac cells (red), alginate pore walls (blue) and gold nanowires (yellow). (B) and (C) Vertical and horizontal cross-sectional images of incorporated nanowires within alginate scaffolds, respectively. The assembled wires were distributed homogeneously within the matrix. Reprinted with the permission of Macmillan Publishers Ltd: [Nature Nanotechnology] Ref. [52], Copyright (2011).

photo-crosslinked nanocomposite hydrogels can also help us control cellular behavior.

\section{Conclusions}

The nanocomposite hydrogels are advanced biomaterials that can potentially be used for a wide range of biomedical and pharmaceutical applications. Compared to conventional polymer hydrogels, the nanocomposite hydrogels have superior physical, chemical, mechanical and electrical properties. Furthermore, better interactions between the polymer chains and nanoparticles result in better nanocomposite performance.

Many approaches have been proposed to improve the nanoparticle/polymer interactions based on the covalent/non-covalent surface functionalization of nanoparticles with different chemical or biological agents according to the final application of hydrogel nanocomposite.

The nanocomposite hydrogel application is based on the type of nanoparticles embedded within their network. Generally, they can be categorized into four groups of carbon-, polymeric-, inorganic- and metallic-based hydrogel nanocomposites. Each category has its own set of properties that make it appropriate for a specific biomedical field.

Carbon-based hydrogel nanocomposites are mainly used in electrically conductive tissues and in the enhancement of mechanical strength or optical properties. Polymeric-based hydrogel nanocomposites, which could be $\mathrm{pH} /$ temperature/concentration/light sensitive, are good drug carriers and their main application is in controlled drug delivery. Inorganic-based hydrogel nanocomposites are mechanically strong and are widely used in bone-related implantations. Finally, metallic-based hydrogel nanocomposites are responsive to electri$\mathrm{cal} / \mathrm{magnetic}$ field stimuli and can be remotely controlled. They also demonstrate antibacterial properties and are widely used as imaging agents, conductive scaffolds, actuators/sensors and drug delivery systems.

Despite all the developments in the field of nanocomposite hydrogels, there is still a lack of control over their long-term cytotoxicity in vivo issues, stimuli responsiveness, biodegradation and mechanical properties. Thus, future studies may shift toward combining multi phases or multi components to design improved nanocomposite hydrogels. The surface functionalization of nanoparticles and the methods used for nanoparticle/nanostructure synthesis also need further attention in order to create hydrogels that are both stable and ecofriendly. 


\section{References}

[1] Yin P, Thesis, The University of Western Ontario, Paper 879, 2012.

[2] Gaharwar AK, Peppas NA, Khademhosseini A. Biotechnol. Bioeng. 2014, 111, 441-453.

[3] Ederth T. In SEACOATATC1, Conferance, Heidelberg, 2010.

[4] Haraguchi K. Curr. Opin. Solid State Mater. Sci. 2007, 11, 47-54.

[5] Sasaki Y, Akiyoshi K.Chem. Rec. 2010, 10, 366-376.

[6] Manias E. Nat. Mater. 2007, 6, 9-11.

[7] Kumar S, Rani R, Dilbaghi N, Tankeshwar K, Kim K-H. Chem. Soc. Rev. 2017, 46, 158-196.

[8] Gaharwar AK, Patel A, Dolatshahi-Pirouz A, Zhang H, Rangarajan K, Iviglia G, Shin S-R, Hussain MA, Khademhosseini A. Biomater. Sci. 2015, 3, 46-58.

[9] Paul A, Hasan A, Kindi HA, Gaharwar AK, Rao VTS, Nikkhah M, Shin S-R, Krafft D, Dokmeci MR, Shum-Tim D, Khademhosseini A. ACS Nano 2014, 8, 8050-8062.

[10] Feng L, Zhang S, Liu Z. Nanoscale 2011, 3, 1252-1257.

[11] Kim H, Namgung R, Singha K, Oh I-K, Kim W-J. Bioconjugate Chem. 2011, 22, 2558-2567.

[12] Kim H, Kim W-J. Small 2014, 10, 117-126.

[13] Nichol JW, Koshy ST, Bae H, Hwang C-M, Yamanlar S, Khademhosseini A. Biomaterials 2010, 31, 5536-5544.

[14] Turcheniuk K, Boukherroub R, Szunerits S. J. Mater. Chem. B 2015, 3, 4301-4324.

[15] Joshi N, Grinstaff M. Curr. Top. Med. Chem. 2008, 8, 1225-1236.

[16] Oral E, Peppas NA. J. Biomed. Mater. Res. Part A 2004, 68, 439-447.

[17] Schmaljohann D. Adv. Drug Delivery Rev. 2006, 58, 1655-1670.

[18] Söntjens SHM, Nettles DL, Carnahan MA, Setton LA, Grinstaff MW. Biomacromolecules 2006, 7, 310-316.

[19] Solouk A, Mirzadeh H, Shokrgozar MA, Solati-Hashjin M, Najarian S, Seifalian AM. Iran. Biomed. J. 2011, 15, 6-14.

[20] Zhang H, Patel A, Gaharwar AK, Mihaila SM, Iviglia G, Mukundan S, Bae H, Yang H, Khademhosseini A. Biomacromolecules 2013, 14, 1299-1310.

[21] Gupta M, Sharma V. Res. J. Chem. Sci. 2011, 1, 135-138.

[22] Oh JK, Drumright R, Siegwart DJ, Matyjaszewski K. Prog. Polym. Sci. 2008, 33, 448-477.

[23] Mahdavi H, Mirzadeh H, Hamishehkar H, Jamshidi A, Fakhari A, Emami J, Najafabadi AR, Gilani K, Minaiyan M, Najafi M, Tajarod M, Nokhodchi A. J. Appl. Polym. Sci. 2010, 116, 528-534.

[24] Van Thienen TG, Lucas B, Flesch FM, Van Nostrum CF, Demeester J, De Smedt SC. Macromolecules 2005, 38, 8503-8511.

[25] Satarkar NS, Biswal D, Hilt JZ. Soft Matter 2010, 6, 2364-2371.

[26] Hench LL, Splinter RJ, Allen WC, Greenlee TK. J. Biomed. Mater. Res. Part A 1971, 5, 117-141.

[27] Zhang S, Xianting Z, Yongsheng W, Kui C, Wenjian W. Surf. Coat. Technol. 2006, 200, 6350-6354.

[28] Sadat-Shojai M, Khorasani M-T, Jamshidi A. Mater. Sci. Eng. 2015, 49, 835-843.

[29] Bagheri-Khoulenjani S, Etrati-Khosroshahi M, Mirzadeh H. Iran Polym / 2010, 19, 743-755.
[30] Bagheri-Khoulenjani S, Mirzadeh H, Etrati-Khosroshahi M, Ali Shokrgozar M. J. Biomed. Mater. Res., Part A 2013, 101, 1758-1767.

[31] Bagheri-Khoulenjani S, Mirzadeh H, Etrati-Khosroshahi M, Shokrgozar MA. Polym. Test. 2016, 51, 20-28.

[32] Haraguchi K. J. Stem Cells Regen. Med. 2012, 8, 2.

[33] Bordes P, Pollet E, Avérous L. Prog. Polym. Sci. 2009, 34, 125-155.

[34] Schexnailder P, Schmidt G. Colloid Polym. Sci. 2009, 287, 1-11.

[35] Nazir MS, Kassim MHM, Mohapatra L, Gilani MA, Raza MR, Majeed K. In Nanoclay Reinforced Polymer Composites, 2nd ed., Jawaid M, Qaiss A el K, Bouhfid R, Eds., Springer: Singapore, 2016, pp. 35-55.

[36] Moghadas B, Dashtimoghadam E, Mirzadeh H, Seidi F, Hasani-Sadrabadi MM. RSC Adv. 2016, 6, 7701-7711.

[37] Kabiri K, Mirzadeh H, Zohuriaan-Mehr MJ, Daliri M. Polym. Int. 2009, 58, 1252-1259.

[38] Gaharwar AK, Avery RK, Assmann A, Paul A, McKinley GH, Khademhosseini A, Olsen BD. ACS nano 2014, 8, 9833-9842.

[39] Gaharwar AK, Mihaila SM, Swami A, Patel A, Sant S, Reis RL, Marques AP, Gomes ME, Khademhosseini A. Adv. Mater. 2013, 25, 3329-3336.

[40] Kerativitayanan P, Gaharwar AK. Acta Biomater. 2015, 26, 34-44.

[41] How are Glass, Ceramics and Glass-Ceramics Defined? TWI Website, FAQs, Available from. http://www.twi-global.com/ technical-knowledge/faqs.

[42] Lotfibakhshaiesh. J. Non-Cryst. Solids 2010, 356, 2583-2590.

[43] Pedone A, Charpentier T, Malavasi G, Menziani MC. Chem. Mater. 2010, 22, 5644-5652.

[44] Straub DA. Nutr. Clin. Pract. 2007, 22, 286-296.

[45] Bonjour J-P, Carrie A-L, Ferrari S, Clavien H, Slosman D, Theintz G, Rizzoli R. J. Clin. Invest. 1997, 99, 1287.

[46] Encinas-Romero MA, Peralta-Haley J, Valenzuela-García JL, Castillón-Barraza FF. J. Biomater. Nanobiotechnol. 2013, 4, 327.

[47] De Aza PN, Guitian F, De Aza S, Valle F). Analyst (Cambridge, U. K.) $1998,123,681-685$.

[48] Balazs AC, Emrick T, Russell TP. Science 2006, 314, 1107-1110.

[49] Palza H. Int. J. Mol. Sci. 2015, 16, 2099-2116.

[50] Murali Mohan Y, Lee K, Premkumar T, Geckeler KE. Polymer 2007, 48, 158-164.

[51] Gaharwar AK, Wong JE, Müller-Schulte D, Bahadur D, Richtering W. J. Nanosci. Nanotechnol. 2009, 9, 5355-5361.

[52] Dvir T, Timko BP, Brigham MD, Naik SR, Karajanagi SS, Levy 0, Jin H, Parker KK, Langer R, Kohane DS. Nat Nano 2011, 6, 720-725.

[53] Tomás H, Alves CS, Rodrigues J. Nanomedicine 2017, 14, 2407-2420.

[54] Cinay GE, Erkoc P, Alipour M, Hashimoto Y, Sasaki Y, Akiyoshi K, Kizilel S. ACS Biomater. Sci. Eng. 2017, 3, 370-380.

[55] Marrella A, Lagazzo A, Barberis F, Catelani T, Quarto R, Scaglione S. Carbon 2017, 115, 608-616.

[56] Jaiswal MK, Carrow JK, Gentry JL, Gupta J, Altangerel N, Scully M, Gaharwar AK. Adv. Mater. 2017, 29, 1702037.

[57] Liang Y, Kiick KL. Biomacromolecules 2016, 17, 601-614.

[58] Ji H, Sun H, Qu X. Adv. Drug Delivery Rev. 2016, 105, 176-189.

[59] Pathania D, Gupta D, Kothiyal NC, Eldesoky GE, Naushad M. Int. J. Biol. Macromol. 2016, 84, 340-348.

[60] Brunetti V, Bouchet LM, Strumia MC. Nanoscale 2015, 7, 3808-3816. 
[61] Zhao W, Odelius K, Edlund U, Zhao C, Albertsson A-C. Biomacromolecules 2015, 16, 2522-2528.

[62] López-Noriega A, Hastings CL, Ozbakir B, O’Donnell KE, O’Brien FJ, Storm G, Hennink WE, Duffy GP, Ruiz-Hernández E. Adv. Healthcare Mater. 2014, 3, 854-859.
[63] Zhang Q, Xue R, Li X, Wang Z, Zhou Z, Chen L. Pure Appl. Chem. 2014, 86, 721-731.

[64] Ramón-Azcón J, Ahadian S, Estili M, Liang X, Ostrovidov S, Kaji H, Shiku H, Ramalingam M, Nakajima K, Sakka Y. Adv. Mater. 2013, 25, 4028-4034. 